\title{
Nodding syndrome in Mundri county, South Sudan: environmental, nutritional and infectious factors
}

\author{
*Spencer PS ${ }^{1}$, Vandemaele $\mathrm{K}^{2}$, Richer $\mathrm{M}^{3}$, Palmer VS ${ }^{4}$, Chungong $\mathrm{S}^{5}$, Anker $\mathrm{M}^{6}$, Ayana $\mathrm{Y}^{7}$, Opoka $\mathrm{ML}^{8}$, \\ Klaucke BN ${ }^{9}$, Quarello $\mathrm{A}^{10}$, Tumwine $\mathrm{JK}^{11}$
}

1. Department of Neurology, School of Medicine; Senior Scientist, Center for Research on Occupational and Environmental Toxicology, and Director, Global Health Center, Oregon Health \& Science University, 3181 S.W. Sam Jackson Park Road, L356, Portland, Oregon 97239, USA

2. Department of Pandemic and Epidemic Diseases, World Health Organization, Geneva, Switzerland.

3. USAID Juba South Sudan Office. Consultant for Carter Center and Health Net International in 2001

4. Global Health Center; Oregon Health \& Science University, Portland, Oregon, USA.

5. Department of Global Capacities Alert and Response, World Health Organization, Geneva, Switzerland.

6. School of Public Health and Health Sciences, University of Massachusetts, Amherst Massachusetts, USA

7. World Health Organization, South Sudan.

8. Disease Surveillance, Forecasting and Response, DCD/EMRO, Abdul Razzak Al-Sanhouri Street, P.O. Box 7608, Nasr City, Cairo, Egypt 11371.

9. 337 Talala Ridge Brasstown, North Carolina, USA.

10.Clinica Medica University of Padova, Italy.

11.Department of Paediatrics and Child Health, Makerere University, Kampala, Uganda.

\begin{abstract}
Background: Nodding Syndrome is a seizure disorder of children in Mundri County, Western Equatoria, South Sudan. The disorder is reported to be spreading in South Sudan and northern Uganda.

Objective: To describe environmental, nutritional, infectious, and other factors that existed before and during the de novo 1991 appearance and subsequent increase in cases through 2001.

Methods: Household surveys, informant interviews, and case-control studies conducted in Lui town and Amadi village in 2001-2002 were supplemented in 2012 by informant interviews in Lui and Juba, South Sudan.

Results: Nodding Syndrome was associated with Onchocerca volvulus and Mansonella perstans infections, with food use of a variety of sorghum (serena) introduced as part of an emergency relief program, and was inversely associated with a history of measles infection. There was no evidence to suggest exposure to a manmade neurotoxic pollutant or chemical agent, other than chemically dressed seed intended for planting but used for food. Food use of cyanogenic plants was documented, and exposure to fungal contaminants could not be excluded.

Conclusion: Nodding Syndrome in South Sudan has an unknown etiology. Further research is recommended on the association of Nodding Syndrome with onchocerciasis/mansonelliasis and neurotoxins in plant materials used for food. Keywords: Epilepsy, filariasis, sorghum, neurotoxins, neurotoxins, Moru, Dinka

African Health Sciences 2013; 13(2): 183 - 204 http://dx.doi.org/10.4314/ahs.v13i2.2
\end{abstract}

\section{Introduction}

Nodding Syndrome is a progressive generalized seizure disorder of children that has been described exclusively in African countries, with particular reference to Tanzania, ${ }^{1-4}$ South Sudan ${ }^{5-7}$ and, most recently, northern $\mathrm{Uganda}^{8}$ The signature sign, repetitive dropping of the head resulting from an atonic seizure events, has also been described in Liberia. ${ }^{9-10}$ Nodding Syndrome occurs in the setting

\begin{tabular}{l}
\hline *Corresponding author: \\
Peter S. Spencer PhD, FANA, FRCPath \\
Global Health Center \\
Oregon Health \& Science University \\
Portland, Oregon 97239, USA \\
Email: spencer@ohsu.edu \\
\hline
\end{tabular}

African Health Sciences Vol 13 Issue 2 June 2013 of a high-prevalence of epilepsy, and several studies have reported an association between epilepsy and onchocerciasis. ${ }^{11}$ The disorder is often found in subjects with immature physical development bordering on or exhibiting dwarfism, lack of secondary sexual characteristics, and cognitive deficits. ${ }^{12-15}$ A harmonized case description of Nodding Syndrome was developed at a July-August 2012 international scientific conference in Kampala, Uganda (table 1). Head nodding, defined as repetitive, involuntary drops of the head to the chest, appears to represent an early stage of the disease that often progresses to include generalized convulsions, while children with grand mal seizures may also develop intermittent head nodding. 


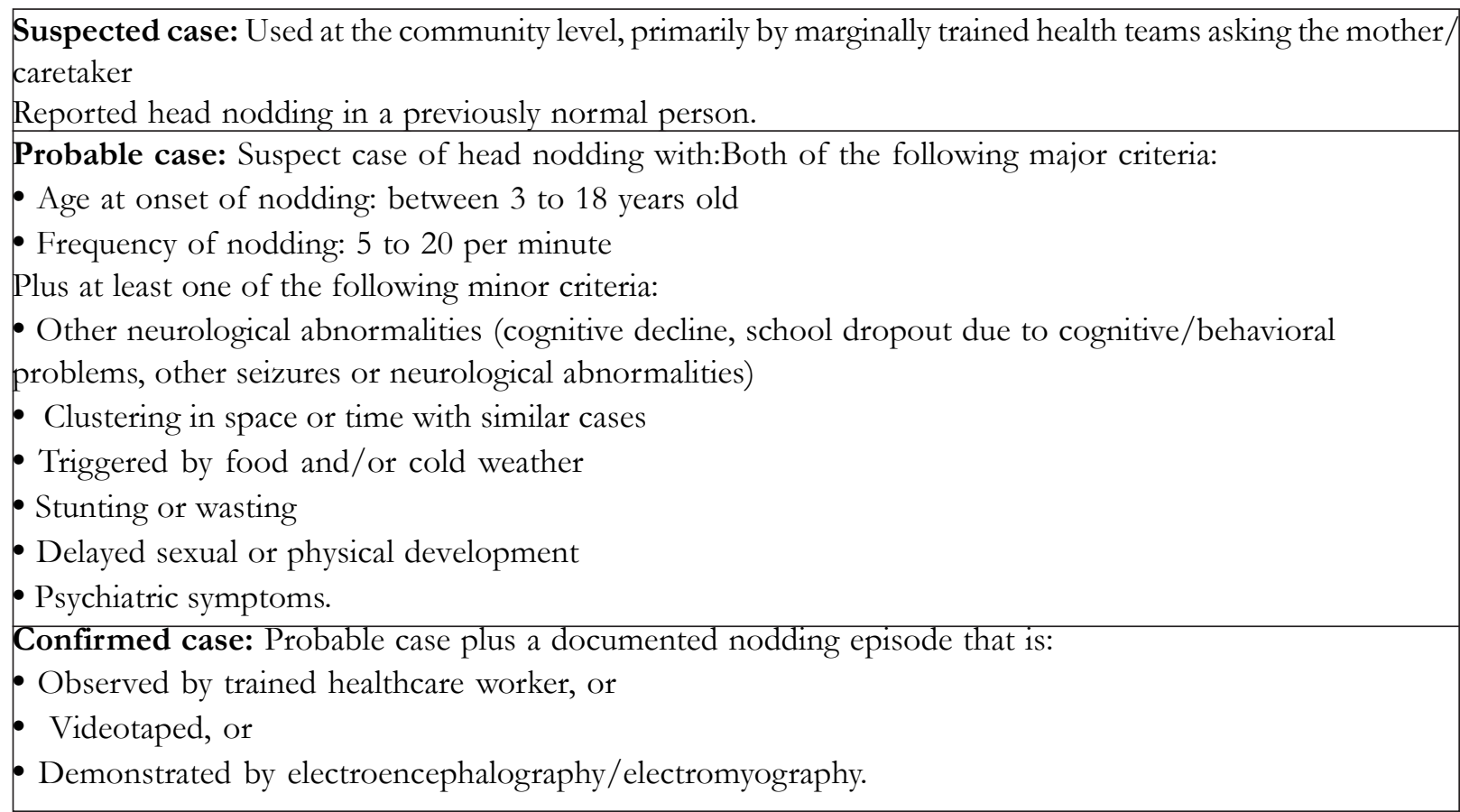

Children with head nodding in an epilepsy-prone community were first described by Jilek-Aall among the Wapogoro people in the Mahenge mountains of central Tanzania, ${ }^{1}$ but a recent examination of Jilek-Aall's clinical notes recorded in the 1960s revealed reports of head nodding in children aged 2-22 years (mean $\sim 10$ years) dating from 1934. ${ }^{16}$ While Nodding Syndrome is thus not a new seizure disorder, outbreaks have been reported de novo in populations such as those in Mundri County, South Sudan, the subject of this paper and its companion clinical study ${ }^{7}$. Common factors in communities with Nodding Syndrome in South Sudan, Tanzania and Uganda include: a marginalized, impoverished and poorly nourished population previously subjected to internal displacement, periodic food shortages, endemic onchocerciasis, and absence or interruption of insect vector control, vaccine administration, and drug prophylaxis/treatment.

The present outbreak investigation examines environmental, nutritional, and infectious factors that existed before the reportedly de novo 1991 appearance and during the subsequent case expansion through 2001 of Nodding Syndrome in Mundri County, then part of southern Sudan. Household surveys, informant interviews, and case-control studies, conducted in Lui town and Amadi village in 20012002, were supplemented in 2012 by informant interviews in Lui and Juba, South Sudan, and by an internet-based data search. While these towns in
Mundri County remain the "epicenter" of Nodding Syndrome in South Sudan, affected children are also reported from Juba, Yei and Morobo (Central Equatoria State) and, anectodally, from Eastern Equatoria and Rumbek (Lakes State). ${ }^{17}$

The reader is referred to the companion paper $^{7}$ for a description of the clinical and electrophysiological characteristics of Nodding Syndrome in Lui and Amadi, and the design and analysis of the case-control studies. This paper reports the multi-factorial exposures associated with Nodding Syndrome and examines how they may relate to etiology, with the goal of identifying those that merit detailed research study.

This investigation was conducted by a multidisciplinary biomedical team assembled by the World Health Organization (WHO) in response to a reported outbreak of a previously unknown disease described by a concerned medical informant as a progressive, fatal brain disorder hallmarked by head nodding and convulsions. The goal of the investigation was to identify potential causes and risk factors as a basis for implementation of immediate measures for management and prevention, if possible.

\section{Methods}

Active investigation focused on Lui town and Amadi village, which are located in Mundri County, Western Equatoria (figure 1). This is a poor, rural area of 
mostly subsistence farmers (Moru) and a few herders (Dinka). Unlike the itinerant Dinka people, who make up the majority of people in South Sudan, the Moru are sessile cultivators who supplement their food supplies by hunting and seasonal gathering of wild foods. They may have chickens but generally do not possess livestock. Most people live in family clusters of mud huts with thatched roofs containing simple beds alongside an open wood fire. Families obtain food from their nearby gardens.

A November 2001 survey by one of us (M.R.) examined the parasitic load of 69 suspect cases of Nodding Syndrome (defined at the time as a child with head nodding only, or nodding plus seizures) and 65 controls in Lui and Amadi. Cases were selected randomly from assembled patients, and controls were drawn randomly from school attendees (Lui) or observers (Amadi), with matching for age and sex where possible (excess male controls in Lui and unaffected siblings of index suspect cases in Amadi). Histories were obtained from the parent or other adult caregiver of patients. Subjects were given a physical examination and screened for infection with nematodes (Loa loa, Mansonella perstans, Onchocerca volvulus and Wuchereria bancrofti) and the protozoan (Trypanosoma brucei gambiense) responsible for African trypanosomiasis.

A scapula skin snip and finger-stick blood drop taken during daytime were examined immediately for microfilaria, the microfilarial load estimated on a 5-point scale $(<200,200-400,400-$ $800,800-1000,>1000)$, and the species differentiated (Loa loa vs. Mansonella perstans) based on size and movement characteristics. Negative skin snips were re-read at the end of the day. The ImmunoChromographic-Test (ICT) for lymphatic filariasis was performed on randomly selected persons $(26$ cases and 24 controls) immediately after blood was collected. At day's end, the Card Agglutination Trypanosomiasis Test (CAT'T) was used on serum samples ( $5 \mu \mathrm{l}$ plus $45 \mu \mathrm{l}$ of reconstituted reagent) obtained by centrifuging blood specimens in a battery-operated microcentrifuge (7000 rpm for 3.5 minutes). Parasitological examination for trypanosomes was performed on all CAT'T-positive persons; these subjects were also examined for lymph nodes and, if enlarged, aspirated for examination of lymphatic fluid for trypanosomes. If enlarged lymph nodes were absent, all CAT'T-positive patients had wet blood and stained blood films examined for parasites. All CAT'T-positive cases underwent lumbar puncture in Lui hospital to obtain cerebrospinal fluid (CSF). CSF specimens were examined for parasites immediately, white blood cell (WBC) count, protein level (measured by dipstick technique) and IgM levels using the latex agglutination test, which measures nonspecific IgM elevations. CSF samples were also later analyzed by Polymerase Chain Reaction (PCR) for the presence of O. volvulus antibodies.

The WHO multidisciplinary team investigated Nodding Syndrome in Lui Township in January 2002. Key informants provided background information on diet, displacements, population exposures, prophylactic medication, and beliefs about the disease. The team compared 13 cases of Nodding Syndrome without seizures to 19 children with no history of head nodding or seizures (controls). Cases were identified through a review of Lui hospital records, interviews with key informants, and house-to-house surveys. Controls were matched to cases by age and neighborhood of residence. Parents or adult caretakers were questioned about the family's history of displacement, crops grown, dietary components, and whether the child had a prior episode of measles or meningitis.

Analysis of epidemiological data was performed as described in the companion paper. ${ }^{7}$ To detect and measure infection with $O$. volvulus, respectively, skin snips were taken by Lui Hospital staff from the iliac crest of cases and controls and read by multiple observers who scored microfilarial loads semi-quantitatively (trace, $1+, 2+, 3+$ ).

This information was augmented in 2012 with reports provided by key informants in Lui and Juba, South Sudan, and by an electronic search for information on the environmental history of Mundri County and surrounding region. Key references describing conditions in the study area and surrounding regions prior to and following 1991 were identified. Critical information was obtained from the Sudan Open Archive (www.sudanarchive.net), a word-searchable, full-text database of historical and contemporary books and documents on Sudan and South Sudan. Rich historical information was found for then-southern Sudan, including Western Equatoria; some data were found specifically for Mundri and nearby counties (figure 1), and Liu and Amadi (figure 2), among other towns and villages in Western, Central, and Eastern Equatoria, were occasionally mentioned in reports. 


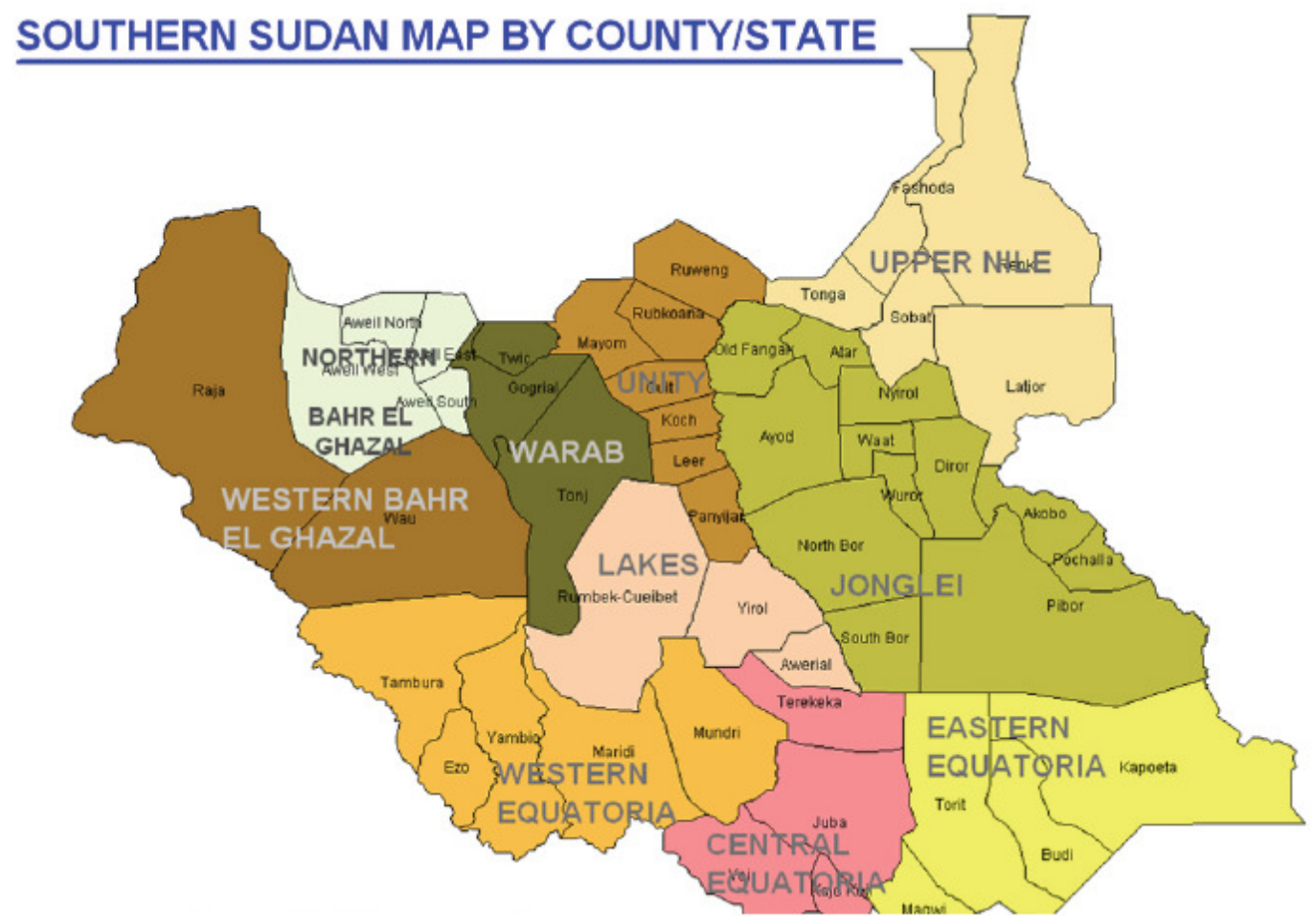

Figure 1: Southern Sudan Map circa 1991

Children with head nodding in Mundri (many) and Maridi (few) counties in Western Equatoria were reported to the WHO team in 2002. Reproduced without modification from United Nations Operation Lifeline Southern Sector. 1992 Emergency Needs Assessment and Appeal. Southern Sudan, Nairobi, December $1991 .{ }^{22}$

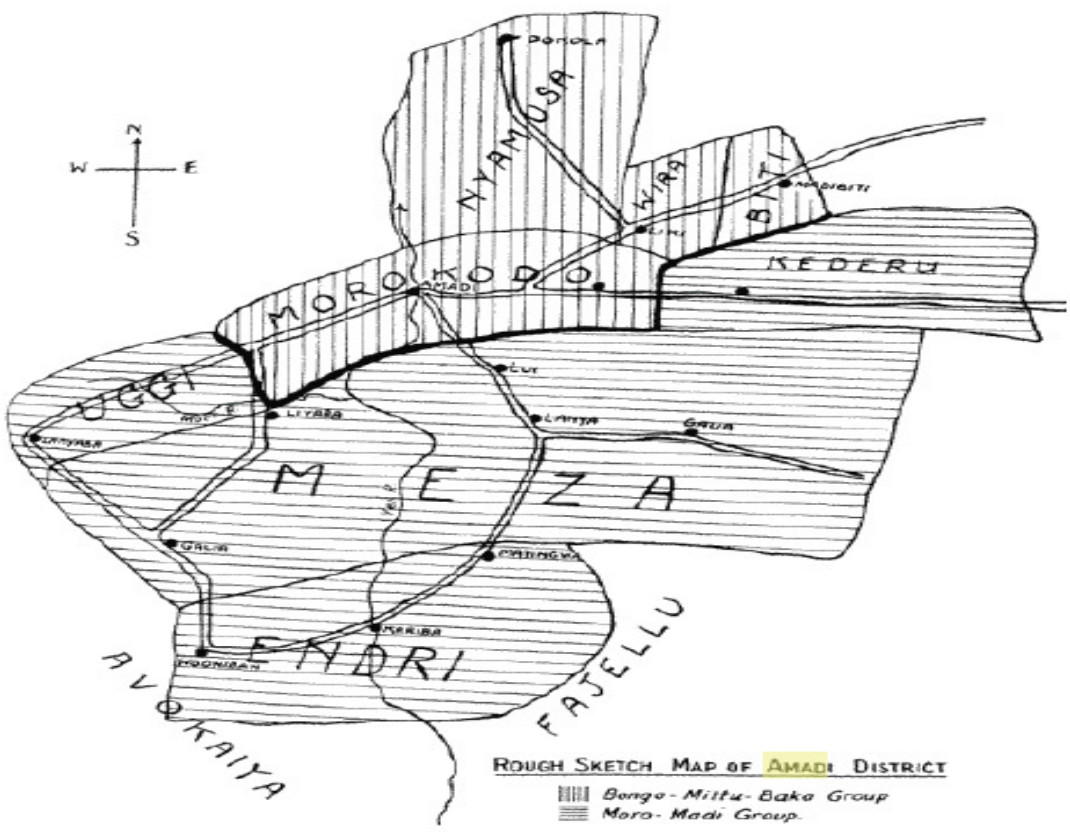

Figure 2: Mundri County map showing Liu in Morokodo district and Amadi in Meza district

Note that Amadi is indicated as coincident with the course of the Yei River. Reproduced from Sudan Notes and Records 1937; 20:182. www.sudanarchive.net. http://sudanarchive.net/ cgi-bin/pagessoa?e $=01$ off_vand-TXa madi-100125-\% 5 bamadi\% 5d\%3aTX+-1-0 - SectionLevel-0 - 0 - 1 a madi$1 \nLeftarrow a=d \otimes c l=\& d=S N R V o l 20.1 .182 \& d l=S N R V o l 20.1 .182$ 


\section{Ethical considerations}

The outbreak investigation was requested by the local community and orally approved by Lui Hospital and by the local administrator (a civilian representative of the military force in control of the area). Because of high illiteracy, informed oral consent was obtained from adult caretakers of children and from adult subjects aged 18 years and above using local translators and hospital staff. The decision to undertake the 2002 case-control study was made after discussion within the team and consultation with community leaders and hospital staff. The team found it unethical not to test some hypotheses that might help identify the cause of the outbreak. Since the WHO-led outbreak investigation took place before the 2009 version of the WHO international ethical guidelines for epidemiological studies, no prior approval was sought from an ethical review committee. Given the dire security situation, it was also not clear if there would be another opportunity to gain an understanding of the head nodding disorder that might aid the twin goals of disease treatment and prevention.

\section{Results}

\section{History of former southern Sudan}

A guerilla war between the government of Sudan and the Sudan People's Liberation Army (SPLA) resumed in 1983 after a decade-long truce. The SPLA forces controlled huge swaths of land, while the government controlled major garrison towns. Virtually the entire civilian population, half of which were children, was cut off from any assistance, and famine conditions existed in some southern garrison towns as early as 1984. Localized famines in besieged towns and enclaves were a feature of the war, alongside massive displacement and chronic impoverishment of the rural population. Original video footage from that period is available (http:// www.infocusworld.org/).

An exceptionally severe famine that belatedly sparked an international humanitarian response was centered in northern Bahr el Ghazal and reached its peak in $1988 .{ }^{18}$ Deng $^{19}$ details the famine, malnutrition, use of wild plants for food, and mortality. Contemporaneously, mass starvation threatened refugees in Equatoria because mined roads prevented access by food convoys ${ }^{20}$. Airlifting of food began in October 1988 when tons of wheat were delivered to the remote town of Abyei in which thousands had died from malnutrition and a measles epidemic $^{21}$. In April 1989, a consortium of United
Nations agencies and approximately 35 nongovernmental organizations, provided humanitarian assistance throughout war-torn and drought-afflicted regions of then southern Sudan under the banner of Operation Lifeline Sudan (OLS). This was launched in response to the deaths of an estimated 250,000 civilians (accuracy unknown) from famine caused by the armed conflict.

There was a dramatic increase in 1991 in the number of vulnerable people fleeing the war or natural disaster ${ }^{22}$ (figure 3). People living along the roads left their settlements and fled to inaccessible areas of the forest and bush, where they reestablished their villages. Significant areas were taken by the SPLA resulting in displacement of civilian populations in Western Equatoria. Relief to civilians living in SPLAheld areas was provided from Kenya, via a forwarding base at Lokichogio. During May 1997, OLS received clearance from the Government of Sudan for relief flights from Lokichogio to 99 airstrips in southern Sudan, but certain locations (including Mundri and Maridi) were excluded. ${ }^{23}$ Food sufficiency was promoted by the provision of seed and agricultural tools to facilitate crop planting and cultivation, and lines and hooks to catch fish. Seed distribution was determined by local elders and authorities who, reportedly, favored farmers over the less fortunate (http:// www.palmtreeproduction.com/OLS/OLS.html). UNICEF-coordinated immunization campaigns for children, most of whom had never been vaccinated.

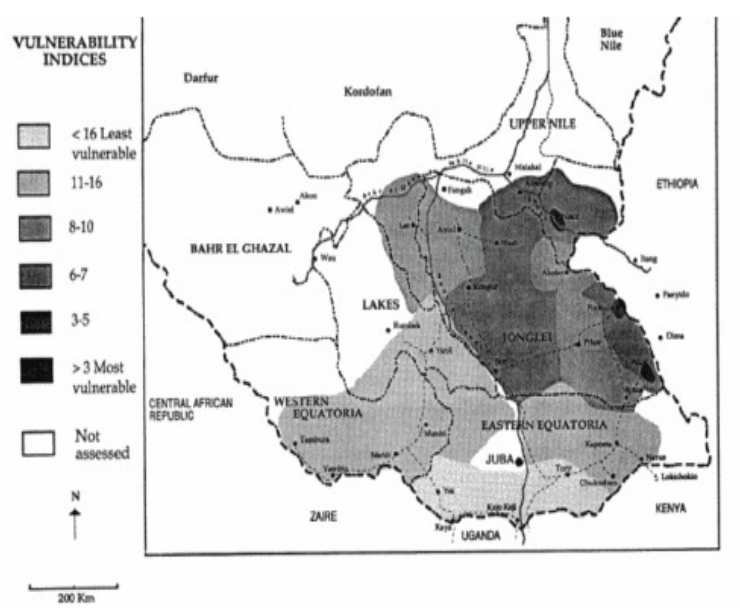

Figure 3: 1991 Vulnerability indices for southern Sudan 
Mundri County in the extreme eastern part in Western Equatoria, and Maridi County, southwest of Mundri, are located in the 11-16 vulnerability shaded area. In southwest Eastern Equatoria, the towns of Yei and Kaya, the key road link with Uganda, are shown as least vulnerable areas. Reproduced without modification from United Nations Operation Lifeline Southern Sector. 1992 Emergency Needs Assessment and Appeal. Southern Sudan, Nairobi, December 1991.

\section{Study area history}

Famines resulting from crop destruction by locusts were recorded in Mundri County (1937) and Maridi Country (1945). ${ }^{19}$ From 1955 onwards, the security situation in southern Sudan began to deteriorate as the mostly Christian population began to seek independence from predominantly Islamic Sudan ${ }^{24}$. Battles with the Sudanese army took place throughout Equatoria in 1965; this included heavy fighting in the Moru area that led to the destruction of Lui hospital (developed in the 1920s by Scottish missionary Kenneth Grant Fraser) and the displacement of its staff to two smaller hospitals (military and civilian) in Mayaya. Food shortages were noted up to 1970 when people in conflict zones were blocked from going to the bush for game and honey.

From 1987, people living in the Mundri area were cut off from external supplies as military convoys moved between Juba, Yei, Maridi, Yambio and Tambura. In July 1990, an estimated 139,000 people were living in Maridi, Mundri, Nzara, Tambura, and Yambio, but, with military activity, residents fled and the towns became deserted, as noted by United Nations staff conducting field visits in August and October 1991. People living along the roads left their settlements and fled to less accessible parts of the countryside where they reestablished their villages. Since crop cultivation was difficult for displaced families living in the bush, their food included wild plants.

A progress report of the Mundri Maridi Emergency Programme for the period October 1993 to May 1994 describes the registered displaced population and the strain placed on available food supplies. At the end of May 1994, Lui housed an estimated 10,000 people displaced from the Kediba area, while Yeri and Gulu (Uganda) housed more than 14,000 people displaced from Amadi. Whereas a large number $(>40,000)$ of displaced Dinka in Maridi County had been forced to give up their cattle and clear land to grow crops, those locally displaced to Mundri County (including Lui) were considered less vulnerable and were able to establish themselves fairly quickly. ${ }^{25}$

Western Equatoria has fertile soils, adequate rainfall throughout the year, and was one of the breadbaskets of southern Sudan prior to the disruption caused by military conflict. However, rainfall can also be erratic and stop early, leading to withering of crops, poor harvest, food deficits, and malnutrition, as occurred in $2005 .{ }^{26}$ Crops grown in Mundri County at that time included the following: sorghum, maize, groundnut, sesame, cowpeas, green gram and various vegetables.

Modern photographs of Mundri County, and Lui town in particular, are available (http:// www.pbase.com $/ \mathrm{rlankenau} / \mathrm{mundrilui \& view}=$ tree) 2001-2002

Key informants from Lui reported that head nodding among children in Mundri County was unknown prior to 1990, the first child known to be affected dating from 1991. The first cases in Lui were reported to have occurred after the last displacement (1994-1997), specifically 1995. Of 55 suspected cases of Nodding Syndrome found in September 2001, the age range was 3-21 years, with 26 children 10-12 years old. The 2002 Household survey in Lui found that new-case numbers per year were 3 (1995), 10 (1998), 8 (1999), 11 (2000), and 8 (2001).

Food insecurity for people living in Lui and Amadi appears to have begun in the second half of 1990. In 1991, thousands of people were forced to flee from their homes to the bush when Mundri and Maridi were captured from the Sudan Army by the SPLA. The Amadi community fled westward toward Yeri and Maridi, while three-quarters of the displaced population lived along the banks of the Yei river. Of the approximately $85 \%$ who abandoned Lui, three-quarters fled to the south and a quarter to the east. They lived in the bush, along the bank of the river Yei, and across the river in a forest of thick bushes. Since cultivation was impossible during periods of displacement, people relied for food on wild vegetables, fruit, mushrooms and grass supplemented by fish and bush meat. They returned to their villages in 1992 after the start of the United Nations food relief operation. Relief supplies included cooking oil, sorghum, maize, lentils, beans, onions and okra. In addition to the immediate need for food assistance, the UN recommended largescale inputs of agricultural tools and seed, road 
improvements and bridge reconstruction, incentives for re-settlement along roads for easy access, and attention to their education and health ${ }^{21}$. A 1991/92 Situation Assessment map indicates that severe conflicts, epidemics and food shortages were not present in Mundri and Maridi Counties at that time (figure 4). However, by 1993, relief centers had been established in Lui, Ranga, Lunjini, Matar and Korovia.

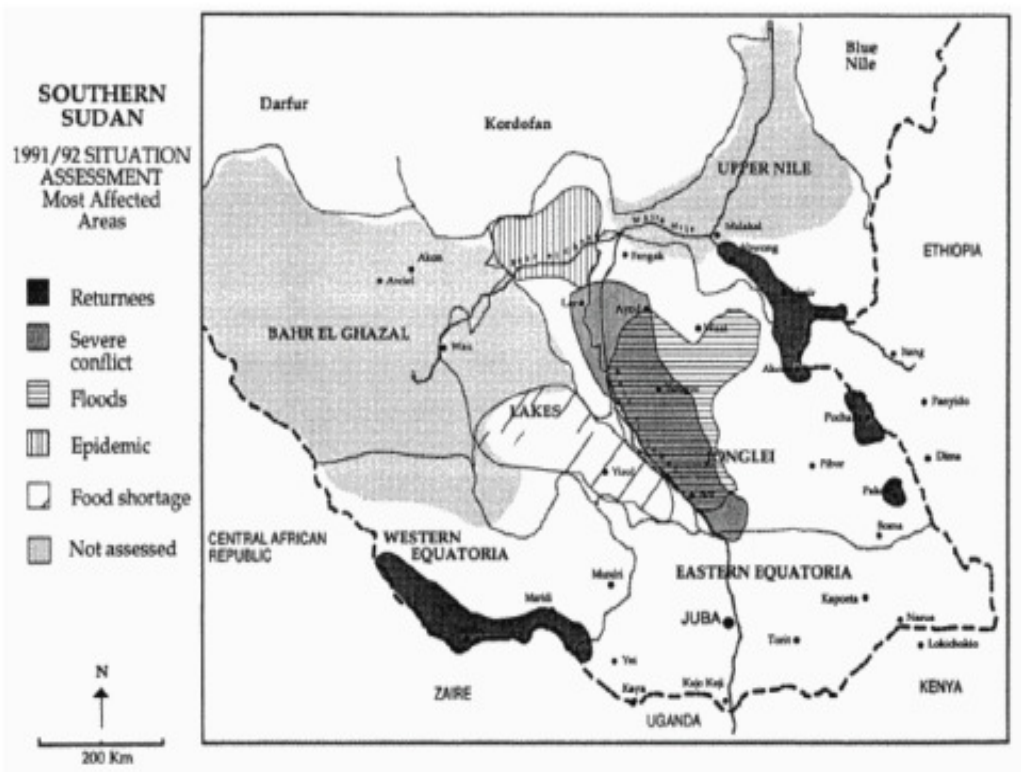

Figure 4: 1991/92 Situation Assessment map of most affected areas in southern Sudan

Note that Mundri and Maridi counties are shown to be free of severe conflict, floods, epidemics and food shortages. Reproduced without modification from United Nations Operation Lifeline Southern Sector. 1992 Emergency Needs Assessment and Appeal. Southern Sudan, Nairobi, December 1991.22

In 2002, Lui town was an unpaved community of subsistence farmers (Moru, majority) and herders (Dinka, minority) served by a hospital, church, mission, and food market. Extended families resided in groups of small mud and grass huts with adjacent gardens planted with rain-fed crops. Over the past 10 years, the community reported they had been subjected to repeated displacement, severe food shortages, and aerial bombardment. The town was supplied by a single well for which there was no evidence by community report of chemical contamination. Additionally, there were no reports by community leaders of acute neurological illness associated with exposure to synthetic chemical agents used for civilian or military purposes.

The 2002 case-control questionnaire was built on information obtained through unstructured interviews and direct observation in and around Lui town. The questionnaire results showed that Nodding Syndrome had occurred only in children of the majority Moru population of Lui and Amadi, not in the Dinka minority, save for one affected child of a Dinka father and a Moru mother. Families of children with Nodding Syndrome more often than controls reported displacement, but the difference was not significant (table 2). Although not intended for human consumption, food shortages had been so severe during or following displacement that many families reported eating malodorous relief seed (maize, sorghum, groundnuts) coated with an unknown colored material and intended for planting. Most families with cases and half of the controls had eaten the seed, but the difference was not significant (table 2).

The diet of the Moru majority in January 2002 was found to include maize, sorghum, lentils and cassava. Wild yams (tize, kendre, idriki), fruit, mushrooms and grass reportedly had also been eaten during periods of displacement in the 1990s. Four types of sorghum (diri, narango, bari, serena) were eaten in 2002; three low-toxin strains were indigenous to the community and a fourth, serena, a red/brown sorghum, along with legumes (green pea, cowpea, and njarro), had been introduced by the World Food Programme (WFP) as emergency food aid. There was no difference in the cultivation of serena by 
families of cases and controls, but reported use of serena for food was significantly higher in children with Nodding Syndrome (table 2). Lentils on sale in the market in 2002 did not include neurotoxic species, such as grasspea (Lathyrus sativus) or common vetch (Vicia sativa), and there was no report of heavy food dependency on cassava. The grandmother of a 13year-old female child with Nodding Syndrome identified faba bean (Vicia faba) and split red lentil (Lens culinaris) as familiar pulses, but indicated that an unsplit pulse had arrived in emergency food supplies. The child reliably began rhythmic head nodding within seconds of eating local food (maize, serena) but, on a single observed occasion when eating packaged food purchased in the USA, failed to display this behavior. Plant products on sale in Lui market in 2002 were free of visible fungal contamination.

Table 2: Displacement, crops, and foodstuffs of cases and controls

\begin{tabular}{|c|c|c|c|c|c|c|}
\hline $\begin{array}{l}\text { Liu, } \\
\text { January }\end{array}$ & $\%$ Cases & $\%$ Controls & Odds ratio(OR) & $\begin{array}{l}\text { Lower OR } \\
\text { Confidence }\end{array}$ & $\begin{array}{l}\text { Upper OR } \\
\text { Confidence }\end{array}$ & $\begin{array}{l}\text { Probability } \\
\text { (Fisher'sExac }\end{array}$ \\
\hline & & & & & & \\
\hline \multicolumn{7}{|c|}{ displacement } \\
\hline \multicolumn{7}{|l|}{ Crops } \\
\hline Narango & 92.31 & 88.89 & 1.50 & 0.12 & 0.19 & 1.00 \\
\hline Serena & 41.67 & 16.67 & 3.57 & 0.66 & 19.34 & 0.21 \\
\hline Bari & 69.23 & 66.67 & 1.13 & 0.24 & 5.21 & 1.00 \\
\hline Diri & 84.62 & 88.89 & 0.69 & 0.08 & 5.64 & 1.00 \\
\hline \multicolumn{7}{|c|}{ Food eaten bychild } \\
\hline Narango & 84.62 & 100.00 & undefined & & & 0.16 \\
\hline Serena & 53.85 & 15.79 & 6.22 & 1.20 & 32.30 & $0.049 *$ \\
\hline Bari & 76.92 & 68.42 & 1.54 & 0.31 & 7.72 & 0.70 \\
\hline Diri & 92.31 & 89.47 & 1.41 & 0.11 & 17.40 & 1.00 \\
\hline $\begin{array}{l}\text { Serena - } \\
\text { major food }\end{array}$ & 23.08 & 11.11 & 2.40 & 0.33 & 16.97 & 0.63 \\
\hline $\begin{array}{l}\text { Unripe } \\
\text { sorghum }\end{array}$ & 92.30 & 83.33 & 2.40 & 0.22 & 26.12 & 0.62 \\
\hline Cassavaa & 84.62 & 94.44 & 0.32 & 0.03 & 4.01 & 0.56 \\
\hline $\begin{array}{l}\text { Colored } \\
\text { seed }\end{array}$ & 83.33 & 50.00 & 5.00 & 0.82 & 30.46 & 0.11 \\
\hline $\begin{array}{l}\text { Baboon } \\
\text { meat }\end{array}$ & 69.23 & 33.33 & 4.50 & 0.97 & 20.83 & 0.07 \\
\hline $\begin{array}{l}\text { Baboon } \\
\text { brain }\end{array}$ & 46.15 & 22.22 & 3.00 & 0.63 & 14.23 & 0.25 \\
\hline
\end{tabular}

Moru villagers reported consuming baboon meat, including brains, during periods of displacement. The reported consumption of baboon meat, but not brain, approached statistical significance in families of children with Nodding Syndrome (table 2).

Cases and controls had significant parasitic loads (table 3). Cases were strongly associated with onchocerciasis, demonstrated by skin snips containing Onchocerca volvulus microfilaria. A history of ivermectin treatment for onchocerciasis was found in both cases and controls. Evidence of infection with Mansonella perstans, another insect vector-borne human filarial nematode, ${ }^{28}$ was also significantly higher in cases than controls. By contrast, there was no difference in infection with Wucheria bancrofti, the nematode responsible for lymphatic filariasis. Evidence of infection with Loa loa, the nematode causal of loaisis, was not found. Trypanosoma brucei gambiense, the protozoan responsible for African trypanosomiasis, was encountered in a small proportion of cases and controls.

Prior infection with measles was reported in the household survey much more frequently in children unaffected by Nodding Syndrome. A history of meningitis was reported by a small number of controls (table 3 ). 
Table 3: Infectious organisms in cases and controls (combined results of 2 case-control studies: November 2001 (upper) and January 2002 (lower)

\begin{tabular}{|c|c|c|c|c|c|c|}
\hline $\begin{array}{l}\text { Lui \& Amadi } \\
\text { November } 2001\end{array}$ & $\begin{array}{l}\text { Lui Cases } \\
\mathrm{n}=39\end{array}$ & $\begin{array}{l}\text { Lui Controls } \\
\mathrm{n}=31\end{array}$ & $\begin{array}{l}\text { Amadi } \\
\text { Cases } \\
\mathrm{n}=30\end{array}$ & $\begin{array}{l}\text { Amadi } \\
\text { Controls } \\
\mathrm{n}=34\end{array}$ & $\begin{array}{l}\text { Odds ratio } \\
\text { (OR)* }\end{array}$ & P-value $<0.05$ \\
\hline Loa loa & $0.0 \%$ & $0.0 \%$ & $0.0 \%$ & $0.0 \%$ & Undefined & \\
\hline Mansonella perstans & 41.0 & 9.6 & 66.6 & 50.0 & 3.22 & $0.005^{*}$ \\
\hline Wuchereria bancroftit ${ }^{a}$ & 0.0 & 9.0 & 0.0 & 7.6 & Undefined & 0.47 \\
\hline Trypanosoma brucei & 12.8 & 9.6 & 0.0 & 5.8 & 0.84 & 0.94 \\
\hline Onchocerca volvulus (OV) & 89.7 & 48.3 & 96.6 & 76.4 & 9.2 & $0.00003^{*}$ \\
\hline Lui only January 2002 & $\begin{array}{l}\% \text { Cases } \\
\mathrm{n}=13\end{array}$ & $\begin{array}{l}\text { \% Controls } \\
\mathrm{n}=19\end{array}$ & OR & Lower OR & Upper OR & $\mathrm{P}$-value $<0.05^{*}$ \\
\hline OV (skin snips) & 92.31 & 43.75 & 15.43 & 1.60 & 148.82 & $0.008^{*}$ \\
\hline Ivermectin treatment $^{\mathrm{b}}$ & 61.54 & 36.84 & 2.79 & 0.64 & 11.75 & 1.00 \\
\hline Previous measles & 15.38 & 58.0 & 0.13 & 0.02 & 0.76 & $0.025^{*}$ \\
\hline Previous meningitis & 0.0 & $5.56 \%$ & & & Undefined & 1.00 \\
\hline
\end{tabular}

${ }^{a}$ sample sizes of 8. 11, 18 and 13 for Lui and Amadi cases and controls, respectively.

${ }^{\mathrm{b}}$ At least one treatment

\section{Discussion}

Nodding Syndrome in Mundri County seems to have appeared de novo around 1991 at a time of local military activity that prompted the community to flee from their homes. Displacement may have occurred repeatedly, with some families displaced as recently as 1994-1997, after which cases of Nodding Syndrome reportedly first appeared in Lui township. Since an estimated $85 \%$ of the population was displaced during the 1990s, it seems probable that most children with Nodding Syndrome were born to displaced families. During periods of displacement, many factors changed in the lives of the Moru people, including exposure to disease vectors and access to vaccination, medicine and food. Displacement was more frequent among families of children with Nodding Syndrome, but the difference between cases and controls was not statistically significant.

We made two notable observations during our investigation of Nodding Syndrome in 2002. One was the exclusive presence of Nodding Syndrome among the indigenous Moru community and its absence among Dinka residents. Unlike the Moru, who depend on rain-fed subsistence agriculture, the Dinka are agripastoral cattle herders who traditionally stay in riverside camps during the dry season and otherwise plant millet and other grains. We did not determine the origin of Dinka herders in Lui, but their presence may have been related to an earlier migration associated with military conflict ${ }^{24}$ or with famine in Bahr el Ghazal or Jonglei. 19,27 During times of insecurity and flood elsewhere in then-southern Sudan, the majority of livestock herders avoided loss of their animals by moving to remote areas. While many animals died or were eaten, supplies of milk and blood seemed to be adequate to maintain nutrition levels among the herders. ${ }^{29}$ The Dinka also breastfeed their babies for prolonged periods (1-3 years) "to give adequate time for child care at the critical time of growth and to reduce exposure to water-borne diseases and protection against infection as well". ${ }^{19}$ Whether these nutritional factors relate to the absence of Nodding Syndrome in 2002 among the children of Lui's Dinka population is unknown.

The second observation was the association of head nodding with the act of eating local foodstuffs, such as sorghum and maize. The Moru people refer to Nodding Syndrome by the name Adravu Legnaro, which is translated as "a disease of eating ugall" - the staple maize/sorghum porridge. Of particular note was a 13-year-old, undeveloped, short-for-age female who reproducibly displayed head nodding within seconds of beginning to eat local food but who failed to display head nodding when eating western packaged food items (highprotein candy bar, raisins). The possible importance of this single observation by the investigation team is reinforced by anecdotal reports from Uganda where children with Nodding Syndrome fail to display head nodding when eating a manufactured peanut-based paste known as Plumpy'Nut. While this places a spotlight on food and nutrition, it is also noteworthy that head nodding reportedly can be triggered by "cold weather", the sight of food and placement of food in the mouth, as well as the act 
of eating. Thus, sensory stimuli, including the sight, smell, taste, and texture of food, as well as chemical components therein, are also justifiably entertained as triggers of head nodding in Nodding Syndrome. Such stimuli could be closely connected to the causes of Nodding Syndrome or act as seizure triggers in a child who is pro-convulsive for other reasons.

\section{Cyanogenic Plants}

Cyanogenic (cyanide-releasing) plants with neurotoxic potential, such as sorghum and cassava, are important components of the Moru diet. Cassava (Manibot esculenta) contains cyanogenic glucosides (linamarin, lataustralin) that are hydrolyzed to hydrogen cyanide (HCN). Cyanide is normally sulfated in vivo by rhodanese to form thiocyanate (SCN) or, in the setting of protein malnutrition, oxidized to form cyanate (OCN), which dosedependently induces peripheral neuropathy in humans and rodents, and myeloneuropathy in primates. ${ }^{30}$ In 1991, a UN assessment team for Western Equatoria observed the re-opening of roadside and town markets selling small amounts of cassava, groundnuts and vegetables, ${ }^{22}$ and cassava was reported as a food item to our team in 2002. Food dependency on cassava in the setting of a protein-deficient diet has caused outbreaks of human neurotoxic disease (kon₹o) in neighboring Democratic Republic of Congo, but the neurological picture is that of a sub-acute onset of spastic paraparesis, with no reports of head nodding or seizures. ${ }^{30}$ For this reason, it seems reasonable to exclude cassava and other plant cyanogens as a cause of Nodding Syndrome; however, cyanogenic plants such as cassava might be contraindicated for a child with Nodding Syndrome, since the seizure threshold would be low and convulsions easily triggered by systemic hydrogen cyanide. Noteworthy is an observation that ascorbate-supplemented guineapigs treated with $8 \mathrm{mg}$ of plant-derived $\mathrm{KCN} / \mathrm{kg}$ body weight showed severe tremors, ataxia, bizarre neuromuscular manifestations, and rhythmic head movements. The toxicity of potassium cyanide $(\mathrm{KCN})$ increased with elevation of vitamin $\mathrm{C}$, whereas urinary excretion of SCN decreased. ${ }^{31}$ In the case of sorghum (Sudan Grass), we found an association between Nodding Syndrome and children's food intake of serena, a red-brown variety (developed in Kenya) that had been introduced into southern Sudan as an emergency foodstuff. Serena is one four types of sorghum used by the Moru in Lui, the other three (narango, bari, diri) showing no case association and low cyanogen (gamma-glutamylbeta-cyanoalanine) content. Young sorghum plants (Sorghum album, S. bicolor), including serena, may contain biologically significant concentrations of the cyanogenic glucoside dhurrin (yielding up to 3500 $\mathrm{mg} \mathrm{HCN} / \mathrm{kg}) .^{32-35}$ Serena was poorly accepted by Kenyan farmers because of an offensive color and bitter taste, ${ }^{36}$ the latter probably associated with cyanogen content.

Sorghum has potential neurotoxicity but neurological disease is only described in sheep, cattle, and horses. Sheep grazing on S. bicolor in the United States develop neurologic signs, including weakness, ataxia, head shaking, knuckling of the fetlocks, and opisthotonus. Neuropathological examination reveals focal neurofilamentous swellings in proximal regions of axons restricted to the nuclei of the medulla oblongata, cerebellum, and midbrain, with additional axonal spheroids in the ventral horn gray matter. ${ }^{37}$ Whether this pattern of neurological damage is strictly associated with repeated exposure to sorghum cyanogens is unclear, since mycotoxin endophytes associated with grasses also have potential neurotoxicity, as discussed below.

\section{Other food items}

The emergency food aid included sorghum, maize, and lentils. Lentils are of interest because certain species of legumes contain neurotoxic principles. We were able to exclude the grasspea (Lathyrus sativus), which is eaten in neighboring Ethiopia, where dependency on this pulse causes lathyrism. ${ }^{38}$ Like konzo, lathyrism is a self-limiting, central motorsystem degenerative disease clinically distinct from Nodding Syndrome. ${ }^{39}$

We presented a range of legumes to an elderly woman (the grandmother of a child with Nodding Syndrome) who identified fava bean (Vicia faba) as a dietary component. She distinguished between whole red lentil (Lens culinaris) and the split form: whereas the latter had been available prior to the onset of Nodding Syndrome, the former had been introduced as part of emergency food relief. This was noteworthy because the Blanche Fleur variety of the common vetch (Vicia sativa), a legume of similar appearance to red lentil but with neurotoxic potential, was sold from Australia for human food use in North Africa and the Middle East contemporaneous with the reported first appearance of Nodding Syndrome in Mundri County in $1991 .{ }^{40}$ 
Vicia sativa contains two pyrimidine cyanogenic gamma-glycosides (vicine and convicine) and beta-glutamyl-gamma-cyanoalanine, a neurotoxic component primarily present in seed as the gamma-glutamyl derivative ${ }^{41-43}$. BetaCyanoalanine induces hyperexcitability, convulsions, and rigidity in chicks and rats after oral or intraperitoneal administration, apparently via a glutamatergic action mediated directly or indirectly by neuronal $N$-methyl-D-aspartate receptors. ${ }^{44}$ Chicks on a diet of $50 \%$ Vicia sativa seed frequently died in an opisthotonic convulsive state within 4.88.8 days of feeding, while a comparable diet of seed extracted with 30\% ethanol produced some growth depression ${ }^{41}$. Young rats (37-53 g body weight) fed $0.5 \%$ beta-cyanoalanine resulted in $25 \%$ deaths, while survivors were irritable and body growth was retarded. ${ }^{41}$ Human poisoning from the consumption of Vicia sativa has not been convincingly described. ${ }^{40}$ Export of Blanche Fleur from southern Australia grew from 40 tonnes in 1988/89 to more than 9470 tonnes between July 1991 and early May 1992, of which 5600 tonnes were sold as split red vetch, sufficient to provide 56 million 100 gram servings, each of which was estimated (prior to soaking/ cooking) to contain $1 \mathrm{~g}$ of neurotoxin. 40 The whole vetch was consigned to Austria, Portugal, Italy, Spain, South Africa, and the USA (where it was used as bird seed) and the split form (for food use) to the Middle East (Saudi Arabia, United Arab Emirates, Dubai, Oman, Jordan) and Egypt. The trade in Vicia sativa was discovered in Egypt when a housewife complained about the slow-cooking properties of her "red lentils", which upon investigation proved to be vetch. While the source and identify of legumes delivered by the WFP is unknown, we found no evidence that vetch entered the emergency food supplies of then-southern Sudan in the early 1990s, and there are no reports of Nodding Syndrome in Egypt or the Middle East. Displaced villagers were forced to rely for food on wild as well as cultivated plants, including the wild yam (tize, kendre, idriki), of which the most common was tize. Identification of this plant is uncertain, but the bitter yam (Dioscorea dumetorum) is a likely candidate because, in Sudan, wild detoxified tubers have been ground into flour and used as a base for the preparation of beer. ${ }^{45}$ The species is found wild throughout tropical Africa between $15^{\circ} \mathrm{N}$ and $15^{\circ} \mathrm{S}$, and is cultivated in West Africa, especially in Nigeria. D. dumetorum is easily harvested by hand but the tubers do not store well, a high proportion becoming hard and inedible within
4 weeks of lifting. Drying of sliced tubers is used as a method of storage. The fresh wild forms are usually toxic and the degree of toxicity is generally in inverse proportion to the depth to which the tubers penetrate in the soil. Many forms of $D$. dumetorum contain a convulsant alkaloid that is a mixture of stereoisomers of dihydrodioscorine. ${ }^{46}$ The wild forms are regarded as famine food, and the tubers are detoxified by slicing, soaking, boiling with salt, and drying.

Respondents in Lui were aware of the toxic properties of tize and how to render it "safe" for human consumption. The identity of the mushrooms and wild fruits that were eaten during displacement from Lui and Amadi is unknown, but use of the aizen or mukheit fruit (Boscia senegalensis) is reported during this period in the Torit area of Eastern Equatoria. ${ }^{47}$ The seed of B. senegaliensis and Dobera roxburghi (Maikab), along with grass seeds, were eaten to survive a $1984-5$ famine. ${ }^{48-50}$ B. senegaliensis (akondok) is also listed in the wild foods collected in Bahr el Ghazal during the 1998 famine. ${ }^{19}$ Other species of wild foods eaten normally and during periods of food shortage include: the water lily (gor, Nymphaea spp.), which has intestinal antidiabetic alpha-glucosidase activity; ${ }^{51}$ the edible fruit tamarind (cuei; Tamarindus indica), a species with many folk medicinal uses; caper (ajuet; Capparis spp.); the reportedly nutritious African locust bean tree (akon; Parkia biglobosa); $;^{52}$ the African fan or palmyra palm (touk; Borassus aethiopicum); ${ }^{53}$ the African peach (dhiot, Nauclea latifolia), which contains psychoactive, nematocidal and anti-fungal substances; ${ }^{54}$ the African ebony or Jackalberry tree (cum; Disospyros mespiliformis), which has anti-microbial properties, ${ }^{55}$ the jujube date (lang; Ziriphus spp.), which has biologically active and cytotoxic properties, ${ }^{56}$ and the bioactive sycamore fig (ngap; Ficus sycomorus) ${ }^{57}$ The fruit of the shea plant (lulu; Vitellaria nilotica) plant was also used to prepare oil during food shortages. We found no evidence of consumption of unripe ackee fruit (Blighia sapida), which induces hypoglycemia and seizures especially in children and may serve as a substitute foodstuff during times of food shortage (November through May in west Africa) $)^{58}$

None of these wild plants shows any obvious possible relationship to Nodding Syndrome.

\section{Neurotoxic Mycotoxins}

While there was no evidence of spoilage of foodstuffs on sale in Lui market in 2002, in situations of severe food shortage during population 
displacement, food spoiled by fungal growth is very likely to be consumed. People displaced from Lui sometimes returned to their gardens to obtain unharvested sorghum, which may have gone to seed, developed fungal sclerotia (which contain ergotrelated chemicals), and thereby rendered unsafe for consumption. Additionally, unknown grass species may have been consumed in a manner used by the Berti to survive famine in western Sudan in 1973, 5,59 Importantly, fungi that infect sorghum and other grasses generate neurotoxic secondary metabolites or mycotoxins, including the tremorgenic mycotoxins, especially the neurotoxic compounds produced by Penicillium spp. (penitrem A, roquefortines, janthitrems) that cause tremors, convulsions, and death in laboratory and farm animals. ${ }^{60}$ Pencillium fungi are also the source of penicillin, a metabolite of which (pencillamine) is a pyridoxine antimetabolite, ${ }^{61}$ as are the hydrazine derivatives of linatine in flaxseed and agaritine in wild mushrooms. ${ }^{62,63}$ Low levels of pyridoxine have been reported in children with Nodding Syndrome. ${ }^{64}$

Neurotoxic fungi either produce a mold on spoiled food (exophytes) or live within plants (endophytes) in a mutalistic relationship. Members of the genus Claviceps are parasites of grasses that specifically infect florets, replace the host reproductive organ with a sclerotium, and synthesize indole-diterpenes with mammalian neurotoxic properties. ${ }^{65}$ Best known to medicine are the ergot alkaloids produced by the fungus $C$. purpurea, which invades rye, wheat, oats, and phalaris grass (vide infra), especially after cold winters followed by rainy springs. Intake of small amounts of ergot results in vasoconstriction that may lead to gangrene, while larger amounts induce convulsions. Various species of the Claviceps ascomycetous fungus parasitize grains of certain cultivated and wild grasses: $C$. africana infects sorghum; C. paspali, dalligrass (Paspalum dilatatum) and bahia grass (P. notatum); C. cinearea, tobosagrass (Hilaria mutica), and C. cynodontis, Bermuda or qwick (kweek) grass (Cynodon dactylon) all of which are known to cause neurological disease among grazing animals. ${ }^{66,67}$ For example, cattle and sheep eating $C$. paspali-infected dalligrass develop a neurological disorder (paspalum staggers) that is attributed to the neurotoxic effects of paspalinine and paspalitrems. ${ }^{68}$ Endophytic fungi may be of natural origin or introduced by inoculation to benefit the plant, the associated mycotoxins conferring properties such as seed vigor, drought resistance, or pest resistance. Six groups of so-called tremorgenic mycotoxins are recognized, all of which elicit an acute reversible tremor syndrome in laboratory mice that appears to be mediated by perturbation of brain neurotransmitter function, notably involving the inhibitory transmitter gamma-aminobutyric acid (GABA). ${ }^{69}$ Adverse effects of tremorgenic mycotoxins are well known in veterinary medicine, especially in regard to animals that graze on grasses harboring endophytes in their seed heads and leaf sheaths. Endophytic diseases include neurological disorders associated with dronk grass (Melica decumbens), sleepy grass (Stipa robusta), and perennial ryegrass (Lolium perenne) (videinfra). The native fungus (Neotyphodium lolii) of perennial ryegrass resides in the leaves, stems and seed of the plant. In Victoria, Australia, endophyte toxicity of perennial ryegrass is greatest when late-season rainfall causes abundant pasture growth and where the summer and autumn conditions include hot spells during a dry period. Climatic conditions prevailing during the period of displacement are therefore relevant to potential mycotoxin exposure.

Of particular possible relevance to Nodding Syndrome is Perennial Ryegrass Staggers, a neurological disease that develops in sheep, cattle, horses, and other animals after one to two weeks of grazing on grass infected with Neotyphodium lolii, which synthesizes the tremorgenic mycotoxin lollitrem B and smaller amounts of the vasoconstrictive ergot alkaloid ergovaline. Sheep develop the syndrome after exposure to 1800-2000 $\mathrm{ppb} /$ day of lolitrem $\mathrm{B}+500-800 \mathrm{ppb} / \mathrm{day}$ of ergovaline. Early signs of the illness in cattle include failure to grow and develop weight gain, even with an adequate food supply, reduced milk yields, and reduced fertility of males and females. Body temperature may be elevated, but there is an attenuated blood flow to the extremities, of note because some children with Nodding Syndrome tend to have arms and legs that feel cold on examination. ${ }^{7}$ Affected animals develop tremors, stiff gait, loss of control of direction of movement, and convulsions. Cessation of exposure early in the disease may lead to recovery, but prolonged exposure induces permanent neurological damage. Affected animals show behavioral changes (flighty), lose control of the direction of movement, develop fine head tremors, head nodding, jerky movements, muscle twitching in the neck shoulder and flank, a stiff-legged, swaying or staggering gait, head extension, and arching and rigid tetanic extension of the legs. The incidence and severity of clinical signs 
are increased by exercise. Daily treatment with mineral-based toxin binders can reduce signs of neurotoxicity. With cessation of exposure, neurological signs reverse in less than 3 weeks, but weight loss persists. No neuropathological changes are found in the acute illness but, with chronic toxicity, fusiform axonal swellings are seen in Purkinje cells and occasionally elsewhere in the brain. ${ }^{68} \mathrm{It}$ is noteworthy that children with Nodding Syndrome may display failure to grow normally, undeveloped secondary sexual characteristics, head nodding, convulsions, drooling of saliva, and cold extremities on examination.

Another possible famine food is reed canary grass (Phalaris arundinacea), an invasive species that is reported in East Africa. Ingestion of this and other species of Phalaris grass causes a progressive, usually irreversible, fatal brain disorder in sheep known as Phalaris Staggers. Signs appear in sheep grazing for 2-4 weeks in an infected pasture, and they may also appear after removal from the pasture. In the early stages of the syndrome, clinical manifestations are similar to those of Ryegrass Staggers, including head nodding, staggering, a high-stepping gait, and falling when excited. Differences include an uneven heartbeat, tremors that do not abate, and an increasing clinical severity until the animal dies. Affected sheep often walk stiff-legged and may drag their hindquarters (unable to flex the hocks), and some may walk on their knees.

Animals that collapse exhibit convulsions, paddling, muscle tremors, nodding of the head, tongue protrusion, and salivation 70-71. Two other neuromycotoxicoses merit mention. One is diplodiosis, a neurotoxic condition of cattle and sheep in southern Africa caused by ingestion of maize ears contaminated with Stenocarpella maydis, which elaborates diplonine. ${ }^{72}$ Clinical signs, which appear after 2-5 days and disappear later, include: reluctance to move, a wide-based stance and a stiff-legged highstepping gait, repeated falling, paresis/paralysis, constipation and salivation. The second is Aspergillus clavatus, which is associated with a fatal tremorgenic syndrome of cattle in Africa ${ }^{73}$ and elsewhere. Linked to the ingestion of fungus-contaminated sorghum beer residues, malt residues or maize sprouts, the disease is associated with degeneration of motor neurons in the midbrain, brain stem and spinal cord. The identity of the culpable tremorgenic mycotoxin is unknown. ${ }^{74,75}$

While maize and sorghum are both staples for the Moru, these two neuromycotoxicoses differ markedly from the clinical pattern of Nodding Syndrome.

\section{Food contaminants and other chemicals}

Respondents in Lui reported in 2002 that hunger drove them to eat seed intended for planting, a phenomenon also recorded elsewhere. ${ }^{26}$ Seed was said to be coated with one or more brightly colored malodorous chemicals. Seed intended for planting is commonly treated with pesticides (insecticides, fungicides), but the chemical nature of the coating of the seed distributed in Lui is unknown. Insecticides used for seed dressing include organophosphorus (e.g. chlorpyrifos) and organochlorine compounds (e.g. endosulfan); both have neurotoxic properties in humans and laboratory animals.

Organochlorines used in agriculture (such as dichlorodiphenyltrichloroethane, DDT) are slowly removed from the body and can trigger myoclonus and convulsions. ${ }^{76}$ Since DDT and other organochlorine pesticides were introduced in the 1940s, some years after the first report of head nodding in children of the Wapogoro people in the Mahenge mountains of Tanzania, ${ }^{16}$ these agents are unlikely causes or triggers of Nodding Syndrome. Nevertheless, the chemical nature of the seed dressing requires identification, especially since certain pesticides can disrupt endocrine function and thereby perturb development of brain, reproductive and immune system function.

Other than ingestion of coated seed, there was no evidence of adverse effects from exposure to pesticidal or other chemicals, including munitions. Respondents in Lui did report exposure to fumes generated by explosives, but there were no accounts of illness consistent with the release of organophosphate nerve agents or mustard gas, chemicals with neurotoxic potential that produce human diseases markedly different from Nodding Syndrome. ${ }^{77,78}$ Drinking water in Lui was provided by a single well that, reportedly, had never been subjected to chemical contamination and was used by all members of the community.

\section{Infectious Agents \\ Prions}

There was no difference in the consumption of monkey brains between cases and controls, but the differential consumption of monkey meat (reportedly not eaten by the Dinka) approached 
statistical significance. Neural tissue of monkeys may harbor prions, infectious proteins that in humans cause fatal neurodegenerative disorders such as Creutzfeldt-Jakob disease (CJD). Young-onset CJD may affect people in their mid-20s. In the early stages of disease, patients exhibit failing memory, behavioral changes, lack of coordination, and visual disturbances. As the illness progresses, mental deterioration becomes pronounced and involuntary movements, blindness, weakness of extremities, and coma may occur. ${ }^{79}$ Since this is a different clinical picture from Nodding Syndrome, a prion infection is an unlikely etiology for Nodding Syndrome.

\section{Parasites}

We found evidence among cases and controls of infection with parasitic protozoa (Trypanosoma bruce). Mundri County is one of nine counties in Equatoria endemic for Human African Trypanosomiasis, which results from the bite of the tsetse fly and injection of insect saliva containing the protozoan T. brucei gambiense. The second stage of the disease, in which the parasites have invaded the central nervous system, is characterized by changes in the sleep-wake cycle (hence "sleeping sickness") and neurological signs such as: tremors, hemiparesis, akinesia, general motor weakness, limb paralysis, and abnormal movements. Psychiatric signs include: inactivity with apathy, psychotic reactions, and aggressive behavior. Untreated patients become progressively less responsive before coma and death supervene. ${ }^{80-83}$ While children with Nodding Syndrome may exhibit blank, staring facies perhaps attributable to absence seizures, the overall clinical pattern of the syndrome is distinct from African trypanosomiasis. Additionally, infection with T. brucei gambiense among cases and controls was similar. We found significant case-association with certain filarial nematodes (Onchocerca volvulus and Mansonella perstans but not Loa loa).

Cases of Nodding Syndrome had a significantly higher rate of skin snips positive for Onchocerca volvulus, the filarial parasite responsible for onchocerciasis (River Blindness). The higher estimated prevalence of Nodding Syndrome in Amadi village than Lui township ${ }^{7}$ may reflect the differential proximity of these two communities to the Yei river (figure 2), the probable breeding ground of Simuliumcarrying $O$. volvulus. These microfilaria were present in blood and skin snips, but not in CSF. Evidence of exposure to O. volvulus in CSF was not found by PCR; similarly, PCR for CSF antibodies to O. volvulus was negative in a small number of Tanzanian children with Nodding Syndrome. ${ }^{3}$

The association between onchocerciasis and epilepsy has been investigated and debated in multiple publications for ca. 15 years; a recent metaanalysis of 8 population-based surveys from west, central and east Africa suggested that epilepsy prevalence increases on average by $0.4 \%$ for each $10 \%$ increase in onchocerciasis prevalence. ${ }^{11}$ While onchocerciasis is endemic in the three areas in which Nodding Syndrome has been documented (South Sudan, Tanzania, Uganda), O. volvulus is unlikely to be the cause, or sole cause, of Nodding Syndrome given that onchocerciasis is endemic in central and east Africa ${ }^{83}$ and was highly prevalent in western Africa before the introduction of vector control. ${ }^{84,85}$ While reports of Nodding Syndrome from these areas are lacking, there are clinical descriptions of head dropping/nodding among subjects with epilepsy in onchocerciasis-endemic areas of Liberia ${ }^{9,10}$ and western Uganda. ${ }^{86}$ These isolated reports, together with the present findings, indicate the need for systematic surveillance for Nodding Syndrome in areas with high endemicity for onchocerciasis. Children with Nodding Syndrome in Lui/Amadi were more frequently infected with Mansonella perstans, a filarial nematode transmitted to humans by biting midges in many parts of sub-Saharan Africa28 from Senegal east to Uganda and south to Zimbabwe. ${ }^{87}$ The clinical and pathological features of $M$. perstans infection are poorly understood; most patients are asymptomatic, others have transient edema and pruritis of the arms, face, and other parts the body, together with transient urticaria and hypereosinophila. Fever, headache, and arthralgias occur less commonly. Occasionally CSF contain microfilariae, and there are rare reports of meningoencephalitis and neuropsychiatric disturbances. ${ }^{87}$ However, a recent study in Uganda did not identify any obvious clinical manifestations that correlated with microfilarial burden, ${ }^{88}$ and the area in Uganda in which Nodding Syndrome occurs has been reported to have a low level of M.perstans infection. ${ }^{89}$

\section{Medication}

Our 2002 survey in Lui and Amadi showed that a non-statistically greater percentage of control subjects than cases had reportedly received at least one dose of ivermectin. In 1995, there was a regional ivermectin campaign to control onchocerciasis, but the use of ivermectin before or after the campaign is not clear. Annual treatment with a single dose of 
$150 \mu \mathrm{g} / \mathrm{kg}$ ivermectin is used for the control and possible elimination of onchocerciasis in most of the central and east African areas meso- or hyperendemic for onchocerciasis and in some areas of western Africa. ${ }^{90}$ Ivermectin treatment reduces skin microfilaria levels in the majority of subjects by $>90 \%$ within 1 month of treatment. Around 3 months after treatment, skin microfilaria levels start to increase again ${ }^{90}$, with successive annual doses leading to progressive decreases in microfilaria levels. Ivermectin has a limited effect on the viability of $\mathrm{O}$. volvulus microfilaria, ${ }^{91-95}$ which have an estimated reproductive life span of 12-15 years. ${ }^{96-97}$ Consequently single treatments with ivermectin do not change the infection status of treated subjects, and the effect of ivermectin mass treatment on infection prevalence is primarily due to reduction in transmission. ${ }^{98-103}$ Between 1987 and 2011, the Mectizan Donation programme approved 139,265,010 ivermectin treatments for Africa. ${ }^{104}$ Adverse reactions to ivermectin treatment of $\mathrm{O}$. volvulus infection constitute the body's reaction to the microfilaria killed and include primarily itching, rash, gland pain and tenderness, joint and muscle pain, fever and headache, pulse and blood pressure changes, all of which disappear within a few days. Doses up to $800 \mu \mathrm{g} / \mathrm{kg}$ reportedly are well tolerated. ${ }^{105-110}$ Subjects with hyperreactive onchodermatitis (sowda) from ivermectin treatment may have more severe musculoskeletal pain, local swellings with pitting edema, and lymph gland tenderness and enlargement. ${ }^{111-112}$. Serious adverse reactions with neurological manifestations after a single oral dose of $150 \mu \mathrm{g} / \mathrm{kg}$ have been reported in people co-infected with high levels of Loa loa microfilaremia. ${ }^{105,113}$ Loa loa was not detected in either cases or controls in the present study.

Ivermectin (22,23-dihydroavermectin B1a + 22,23-dihydroavermectin B1b) acts by disrupting nerve impulses through increasing membrane permeability to chloride ions by modulating the activity of glutamate and GABA-gated chloride channels. P-glycoprotein, which is encoded by the multi-drug resistance gene ( $m d r 1$ ), greatly restricts the entry of ivermectin into the brain by an ATP-driven efflux mechanism at the blood-brain barrier. ${ }^{114}$ The lack of glutamate-gated chloride channels, plus the P-glycoprotein-mediated restriction of accumulation of ivermectin in the central nervous system of vertebrates, explains the safety margin of ivermectin. Signs of toxicity in adult laboratory animals, including ataxia, convulsions, tremors and coma, are observed at doses higher than human therapeutic doses (e.g. 2 $\mathrm{mg} / \mathrm{kg}$ single oral dose in primates). ${ }^{115-116}$ At lower doses, toxicity is observed in animals that lack a functional P-glycoprotein, which allows the drug to accumulate in the nervous system. ${ }^{117}$ The role of $\mathrm{P}$ glycoprotein in Loa loa-infected subjects with serious adverse reactions after ivermectin treatment has been investigated. ${ }^{116-122}$ There is also evidence of developmental neurotoxicity (decreased body weight gain, delayed development, intermittent head and whole-body tremors, hind limb extension and then splay) in the F1 offspring of pregnant Sprague Dawley rats treated under controlled conditions with enamectin benzoate, another avermectin pesticide. ${ }^{123}$ Whereas the F0 females showed no abnormal physical signs or deficits in reproductive performance when treated by oral gavage with $0.1-3.6 \mathrm{mg} / \mathrm{kg}$ once daily from gestation day 6 to lactation day 20 , some pups delivered from the high-dose group developed intermittent head tremors beginning on post-natal day 6 (PND-6). This sign progressed to whole-body tremors in all pups in this group by PND-25, with hind limb extension appearing on PND-10 in some animals, hind-limb splay in all animals between PND ${ }^{15-26}$, and progressively lowerthan-control weight gains beginning on PND-11. Whole-body tremors and hind-limb splay continued in some pups into the post-weanling period (PND 27 and 34, respectively), average absolute brain weights were reduced relative to controls, neuropathological changes were absent, and developmental landmarks were delayed. No adverse physical signs, reduced averaged weight gains, or developmental delays, were observed in pups of dams treated with 0.6 or $0.1 \mathrm{mg} /$ day avermectin benzoate. ${ }^{123}$ Rat studies with radiolabeled ivermectin showed high drug concentrations in the milk of treated dams led to high drug levels in the plasma and brain of F1 offspring, which were probably responsible for the observed neonatal toxicity. Whereas the blood-brain barrier to ivermectin is formed postnatally in rats, it is formed prenatally in humans, ${ }^{123-124}$ although its functional integrity in states of human undernutrition is unclear. ${ }^{125}$

The lack of evidence for recent ivermectin treatment in our investigation of Nodding Syndrome in Mundri County, South Sudan, coupled with the observation that head nodding was reported (1934) and medically observed (1960s) in Tanzania before the first clinical trials of ivermectin in Africa (1981), argue against ivermectin as a causal or risk factor for Nodding Syndrome. 


\section{Vaccination}

Population displacement was accompanied by cessation of vaccination campaigns such that children born during periods of disruption spent their developmental years in a food-stressed environment unprotected against common illnesses, notably measles. We found in Lui that children with Nodding Syndrome were significantly less commonly reported to have had measles infection, although measles in infants below the age of 1 year may go unrecognized. A lower measles rate among cases is unexpected since children with Nodding Syndrome in 2002 were often undeveloped for age and poorly nourished. Measles is more severe in malnourished children, particularly those with vitamin A deficiency, and attack rates are high among children less than 12 months of age. Complications of measles include diarrhea, dehydration, stomatitis, inability to feed, and bacterial infections of the skin and elsewhere. ${ }^{126}$

Measles infection in infancy increases the risk for the subsequent development of subacute measles encephalitis (incubation 5-6 months) and subacute sclerosing panencephalitis (SSPE), a rare $(1 / 100,000)$ progressive neurodegenerative disorder that has been reported to cause cognitive changes and head nodding on awakening. ${ }^{127}$ Onset of SSPE occurs 1 month to 27 years (mean 7 years) after a primary systemic measles infection; others report a 2-10 year silent period. ${ }^{128}$ The onset is insidious, with progressive deterioration of behavior and intellect, followed by ataxia, myoclonic seizures, and death within 2-3 years. ${ }^{126}$ We did not screen for SSPE in our cases and controls, but negative findings for SSPE have been reported in Ugandan children with Nodding Syndrome. ${ }^{64}$

\section{Conclusion}

Nodding Syndrome in Mundri County reportedly appeared de novo in 1991 in the setting of population displacement associated with military conflict. Vaccination and drug campaigns to prevent/treat endemic diseases ceased during this period. Nodding Syndrome appeared a few years later in Lui township and increased through 2001 when this outbreak investigation began. Recall bias, communication barriers, and other factors limit the findings of this study. We found that more cases than controls were infected with microfilarial nematodes, notably Onchocerca volvulus and Mansonella perstans, but infantile measles infection was reportedly less common in cases than controls. Villagers reported a history of displacement and severe food shortages during which they were reliant on both cultivated and wild plants. Emergency supplies included chemically coated seed that was eaten and a red sorghum (serena) that reportedly was more commonly consumed by cases than controls. While known neurotoxic food plants were not linked to Nodding Syndrome, grasses such as sorghum can harbor fungi that generate tremorgenic mycotoxins with the potential to induce neurological disease. Thus, while the cause(s) of Nodding Syndrome is/are unknown, fungal contamination of food merits particular consideration, in addition to onchocerciasis and mansonelliasis.

\section{Acknowledgements}

The authors thank the children and families affected and unaffected by Nodding Syndrome; the community and leaders of Lui township for their cooperation; the hospital and staff of Lui Hospital for their assistance; and Good Samaritan Purse (GSP) for housing the WHO team in Lui, and Warren Cooper, MD, former resident physician-surgeon at GSP in Lui. Dr. Max Tate, University of Adelaide, analyzed lentil and sorghum samples, and Dr. Thomas Nutman, U.S. National Institute of Allergy and Infectious Disease, performed the PCR analysis of CSF samples. Additional assistance in 2012 was provided by Nozomi Hashimoto of the United Nations World Food Programme, Juba; Ms. Karen Daniels, GSP Health Advisor, Juba; Sosthen Amin, Juba, and Dr. Louis Danga, Paediatrician, Juba Hospital. Dr. Lul Reik, Minister of Health and Dr. Richard Lino Lako, Director of Research, Monitoring and Evaluation of the South Sudan Ministry of Health, were provided with a copy of the draft paper and are thanked for their interest, guidance, and support.

P.S.S. and V.P. are supported by a grant from the U.S. National Institute of Neurological Diseases and Stroke, 1 R01 NS079276. Amelia Bartolini assisted with the analysis of documents generously provided by Victor Miller, Center for Research Information, Silver Spring, Virginia, USA. Dr. Annette Kuesel is thanked for editing the manuscript.

\section{References}

1. Aall L. Epilepsy in Tanganyika. Review and Newsletter - Transcultural Research in Mental Health Problems 1962; 13:54-7.

2. Aall-Jilek LM. Epilepsy in the Wapogoro Tribe in Tanganyika. Acta Psychiat Scand 1965; 41:5786. 
3. Winkler AS, Friedrich K, Konig R, Meindi M, Helbok R, Unterberger I, et al. The head nodding syndrome-clinical classification and possible causes. Epilepsia 2008; 49:2008-15.

4. Winkler AS, Friedrich K, Meindi M, Kidunda A, Nassri A, Jilek-Aall, et al. Clinical characteristicsof people with head nodding in southern Tanzania. Trop Doct 2010; 40:173-5.

5. Nyungura JL, Akim T, Lako A, Gordon A, Lejeng L, William G. Investigation into the Nodding syndrome in Witto Payam, Western Equatoria, 2010. Southern Sudan Med J 2011; 4:36.

6. Reik L, Abubakar A, Opoka M, Mindra G, Sejvar J, Dowell SF. South Sudan, 2011. Morbid Mortal Wkely Rep 2012; 61:52-4.

7. Tumwine, JK, Vandemaele K, Chungong, S, Richer M, Anker M, Ayana Y, et al. Clinical and epidemiologic characteristics of Nodding Syndrome in Mundri County, South Sudan. Africa Heallth Sciences 2012; 12:242-8

8. Wasswa H. Ugandan authorities deal with a mysterious ailment that leaves people nodding continuously. Brit Med J13:344:e49 doi: 10.1136/ bmj.e349, 2012.

9. Gerrits C. Conceptions and explanations of sii, epilepsy. A medical-anthropological study among the Bassa and Kpelle in Liberia. Curare 1983; 6:33-40.

10. van der Waals FW, Goudsmit J, Gajdusek DC. See-ee: Clinical characteristics of highly prevalent seizure disorders in the Gbawein and Wroughbarh clan region of Grand Bassa county, Liberia. Neuroepidemiology 2:35-44, 1983.

11. Pion SDS, Kaiser C, Boutros-Toni F, Cournil A, Taylor MM, Meredith SE, et al. Epilepsy in onchocerciasis endemic areas: Systematic review and meta-analysis of population-based surveys. PLoS Negl Trop Dis 2009; 3(6): e461. doi:10.1371/journal.pntd.0000461

12. Raper $A B$, Ladkin RG. Endemic dwarfism in Uganda. East Afr Med J 1950; 27:339-59.

13. Jellife DB, Jones PMR, Stroud CE. Nakalanga. Notes on the endemic dwarfism of Uganda. Trop Geog Med 1962; 14:97-104, 1962.

14. Kipp W, Burnham G, Bamuhiga J, Leichsenring L. The Nakalanka syndrome in Kabarole District, West Uganda. Am J Trop Med Hyg 1996; 54:80-3.

15. Newell ED, Vyungimana F, Bradley JE. Epilepsy, retarded growth and onchocerciasis, in two areas of different endemicity of onchocerciasis in Burundi. Trans R Soc Trop Med Hyg 1997; 91:525-7.

16. Palmer VS, Spencer PS, Bartolini A, Jilek-Aall L. Kifafa an epileptic disorder with head nodding. Presented at the International Scientific Meeting on Nodding Syndrome, Kampala, Uganda. Africa Health Sciences 2013; 13 (2): 176-182

17. Reik L. An overview of Nodding Syndrome in South Sudan. Presented at the International Scientific Meeting on Nodding Syndrome, Kampala, Uganda. July 30-August 2, 2012.

18. Keen D. The Benefits of Famine. A Political Economy of Famine in South-Western Sudan,1983-1989. Princeton University Press, 1994.

19. Deng LB. Famine in the Sudan: Causes, preparedness and response. A political, social and economic analysis of the 1998 Babr el Ghazal famine. IDS discussion paper \#369. Institute of Development Studies, Brighton, UK, 1999; 112p.

20. New York Times. War and Drought Inflicting Famine in Sudan, January 3, 1988.

21. New York Times. Sudan, Racked by Famine, Agrees to $\$ 100$ Million U.S. Food Airlift, October 13, 1988.

22. United Nations: Operation Lifeline Sudan - South Sector. 1992 Emergency Needs Assessment \& Appeal. Southern Sudan. Nairobi, December 1991, 71p. http:/

/ s udanarchive.net / c gi-bin / pagessoa? $a=$ pdf\&d $=$ Dn1d212.1.

$54 \& \mathrm{dl}=1 \& \operatorname{sim}=$ Screen2Image

23. United Nations Operation Lifeline Sudan: May-1997 Report. University of Pennsylvania -African Studies Center, $1997 . \quad$ http:// www.africa.upenn.edu/Urgent_Action/ ols597.html

24. McCall S. Unpublished manuscript on the history of the first civil war in South Sudan (Anya-Nya). http://sudanarchive.net/cgibin/ pagessoa? $=$ pdf\&d $=$

DwmrgdN1_1.1.62\&dl=1\&sim=Screen2Image

25. AAIN. Progress Report: Mundri Maridi Emergency Programme, October 1993 to May 1994. Action Africa In Need, 1994. http://sudanarchive.net/cgi-bin/ pagessoa? $=01$ off - vand $-T X-l u i-100125$ $\% 5$ blui $\% 5 \mathrm{~d} \% 3 \mathrm{aTX}+-1-0$-SectionLevel-0-0-1$1 \& \mathrm{a}=\mathrm{d} \& \mathrm{cl}=\& \mathrm{~d}=\mathrm{Dn} 1 \mathrm{~d} 124.1 .6$

26. UNOCHA. Inter-Agency Assessment on the Conflict Affected Population in Mvolo \& West Mundri Counties. United Nations Office for the Coordination of Humanitarian Affairs, Emergency Preparedness and Response Unit. August 31-September 4, 2006 
27. UN. Lifeline Sudan. An Investigation into Production Capability in the Rural Southern Sudan: A Report on Food Sources and Needs, United Nations, June 1990, 89p.

28. Simonsen PE, Onapa AW, Asio SM. Mansonella perstans filariasis in Africa. Acta Tropica 2011; 120 (Suppl 1):S109-20.

29. WFP. Operation Lifeline Sudan. Food Needs Assessment Survey, Eastern Operations Area: Preliminary Report. World Food Programme, 13 November, 1989.

30. Tshala-Katumbay DD, Spencer PS. Toxic disorders of the upper motor neuron system. In Eisen A, Shaw, P, eds, Handbook of Clinical Neurology: Motor Neuron Disorders and Related Diseases, vol 82, Elsevier, Edinburgh, 2007, pp 353-72.

31. Basu TK. High-dose acorbic acid decreases detoxification of cyanide derived from amygdalin (laetrile): Studies in guinea pigs. Can J Physiol Pharmacol 1983; 61:1426-30.

32. Conn EE. Cyanide and cyanogenic glycosides. In Rosenthal GA, Berenbaum MR, eds, Herbivores: Their interaction with secondary plant metabolites. Academic Press, New York, 1979: pp 387-412.

33. Conn EE. Cyanogenic glycosides. International review of biochemistry. In Neuberger A, JukesTH, eds, Biochemistry and Nutrition 1A, University Park Press, Baltimore, 1979; 27:21-43.

34. Nartey F. Toxicological aspects of cyanogenesis in tropical foodstuffs. In Smith RL, Bababumni EA, eds, Toxicology in the Tropics, Taylor \& Francis, London, 1980, pp 53-73.

35. Dada LO, Dendy DAV. Cyanide content of germinated cereals and influence of processing techniques. In Alnwick D, Moses S, Schmidt OG, eds, Improving Young Child Feeding in Eastern and Southern Africa: Household-Level Food Technology; Proceedings of a Workshop, Nairobi, Kenya, October 12-16, 1987, pp 359-66.

36. Oduol W. Adaptive responses to modern technology: Kitui farmers in the semiarid regions of eastern Kenya. In Ogbu OM, ed, Technology Policy and Practice in Africa, ch 21, International Development Research Centre (Canada), 1996, pp 302-12.

37. Bradley GA, Metcalf HC, Reggiardo C, Noon TH, Bicknell EJ, Lozano-Alarcon F, et al. Neuroaxonal degeneration in sheep grazing Sorghum pastures. J Vet Diagn Invest 1995; 7:229-36.

38. Tekle-Haimanot R, Kidane Y, Wuhib E, Kalissa A, Alemu T, Zein ZA, Spencer PS. Lathyrism in 200 rural northwestern Ethiopia: A highly prevalent neurotoxic disorder. Int J Epidemiology 1990; 19:664-72.

39. Spencer PS. Lathyrism. In Vinken PJ, Bruyn GW, Klawans HL, eds, Handbook of Clinical Neurology, Pt 2, Vol. 21, Elsevier, Amsterdam, 1995, pp 120.

40. Tate ME, Enneking D. A mess of red pottage. Nature 1992; 359:357-8.

41. Ressler C, Nigam SN, Giza Y-H. Toxic principle in vetch. Isolation and identification of gammaLglutamyl-L-beta-cyanoalanine from common vetch seeds. J Am Chem Soc 1969; 91:2758-65.

42. Ressler C, Tatake JG. Vicianin, prunasin, and $\hat{a}-$ cyanoalanine in common vetch seed as sources of urinary thiocyanate in the rat. J Agric Food Chem 2011; 49:5075-80.

43. Farran MT, Darwish AH, Uwayjan MG, Sleiman FT, Ashkarian VM. Vicine and convicine in common vetch (Vicia sativa) seeds enhance $\hat{a}-$ cyanoalanine toxicity in male broiler chicks. Int J Toxicol 2002; 21:201-9.

44. Roy DN, Sabri MI, Kayton RJ, Spencer PS. âCyano-L-alanine toxicity: evidence for the involvement of an excitotoxic mechanism. Nat Toxins 1996; 4:247-53.

45. Corkill NL. The poisonous wild cluster yam Dioscorea dumetorum Pax., as a famine crop in the Anglo-Egyptian Sudan. Ann Trop Med Parasitology 1948; 42:278-87.

46. Bevan CWL, Broadbent JL, Hirst J. A convulsant alkaloid of Dioscorea dumetorum. Nature1956; 177:935.

47. National Academies. Lost Crops of Africa. Vol III. Fruits. National Academies Press, Washington DC, 2008, 380p.

48. Salih OM, Nour AM, Harper DB. Chemical and nutritional composition of two famine food sources used in Sudan, Mukheit (Boscia senegalensis) and Maikah (Dobera roxburghi). J Sci Food Agric 1991; 57:367-377.

49. De Waal A. Famine early warning systems and the use of socio-economic data. Disasters 1988; 12:81-91.

50. Scoones I, Melnyk M, Pretty JN. The Hidden Harvest. Wild Foods and Agricultural Systems. A Literature Review and Annotated Bibliography. Sustainable Agriculture Programme, London, 1992.

51. Huang YN, Zhao YL, Gao XL, Zhao ZF, Jing $\mathrm{Z}$, Zeng WC, et al. Intestinal alpha-glucosidase inhibitory activity and toxicological evaluation of

African Health Sciences Vol 13 Issue 2 June 2013 
Nymphaea stellata flowers extract. J Ethnopharmacol 2010; 13:306-12.

52. Alabi DA, Akinsulire OR, Sanyaolu MA. Qualitative determination of chemical and nutritional composition of Parkia biglobosa (Jacq.) Benth. African J Biotech 2005; 4:812-5.

53. Ali A, Alhadji D, Tchiegang C, Saidou C. Physicochemical properties of Palmyra palm (Borassus aethiopicum Mart.) fruits from northern Cameroon. African J Food Sci 2010; 4:115-9.

54. Ata A, Udenigwe CC, Matochko W, Holloway P, Eze MO, Uzoegwu PN. Chemical constituents of Nauclea latifolia and their anti-GST and antifungal activities. Nat Prod Commun 2009; 4:11285-8.

55. Adeniyi BA, Odelola HA, Oso BA. Antimicrobial potentials of Disopyros mespillformis (Ebenaceae). Afr J Med Sci 1996; 25:221-4.

56. Ahmad B, Khan I, Bashir S, Azam S, Ali N. The antifungal, cytotoxic, antitermite and insecticidal activties of Zisyphus jujube. Pak J Pharmacol 2011; 24:489-93.

57. Mousa O, Vuorela P Kiviranta J, Wahab Sa, Hiltunen R, Vuorela H. Bioactivity of certain Egyptian Ficus species. J Ethnopharmacol 1964; 41:71-6.

58. Mehda HA, Diallo B, Buchet JP, Lison D, Barennes $\mathrm{H}$, Ouangre A, et al. Epidemic of fatal encephalopathy in preschool children in Burkina Faso and consumption of unripe ackee (Bligbia sapida). Lancet 1999; 53: 536-540.

59. Holy L. Drought and change in a tribal economy. The Berti of Northern Darfur. Disasters 1980; 4:65-72.

60. Gupta RC. Veterinary Toxicology. Basic and Clinical Principles. 2nd ed. Academic Press, Amsterdam, 2012.

61. Kuchinskas EJ, Horvath A, Du Vignead V. An anti-vitamin B6 action of L-penicillamine. Arch Biochem Biophys 1957; 68:69-75.

62. Levenberg B. Isolation and structure of agaritine, a gamma-glutamyl-subsituted arylhdrazine derivative from Agaricaceae. J Biol Chem 1964; 239:2263-73.

63. Klosterman HJ, Lamoureux GL, Parsons JL. Isolation, characterization, and synthesis of linatine. A vitamin B6 antagonist from flaxseed (Linum usitatissimum). Biochemistry 1967;6:170-7.

64. Reik L, Dowell S, Mbonye A. Nodding Syndrome Overview. Summary of investigations and current understanding. Presented at the International Scientific Meeting on Nodding Syndrome, Kampala, Uganda. July 30-August 2, 2012.

African Health Sciences Vol 13 Issue 2 June 2013
65. Uhlig S, Botha CJ, Vralstad T, Rolen E, Miles CO. Indole-diterpenes and ergot alkaloids on Cynodon dactylon (Bermuda grass) infected with Claviceps cynodontis from outbreak of tremors in cattle. J Agric Food Chem 2009; 57:11112-9.

66. Kingsbury JM. Poisonous Plants of the United States and Canada. Prentice Hall, Englewood Cliffs, NJ, 1964, 626p.

67. Kellerman TS, Coetzer JAW, Naude TW, Botha CJ. Plant Poisonings and Mycotoxicoses of Livestock in Southern Africa. 2nd ed. Oxford Univ Press, Cape Town, 2005, 310p.

68. Frank AA, Blythe LL, Spencer PS. Aspects of veterinary neurotoxicology. In Spencer PS, Schaumburg HH, eds, Experimental and Clinical Neurotoxicology, 2nd ed. New York; Oxford, 2000, pp 83-105.

69. Ludolph AC, Spencer PS. Penitrems and other tremorgens. In Spencer PS, Schaumburg HH, eds, Experimental and Clinical Neurotoxicology, 2nd ed. New York; Oxford, 2000, pp 951-63.

70. Watson RW, McDonald WJ, Bourke CA. Agfacts: Phalaris Pastures. New South Wales Agriculture P.2.5.1. July 2000.

71. Fowler ME. Medicine and Surgery of Camelids. Third Ed, Wiley-Blackwell, 2010.

72. Snyman LD, Kellerman TS, Vleggaar R, Flett BC, Basson KM, Schultz RA. Diplonine, a neurotoxin isolated from cultures of the fungus Stenocarpella maydis (Berk.) Sacc. that induces diplodiosis. J Agric Food Chem 2011; 59:9039-44.

73. Kellerman TS, Pienaar JG, Van der Westhuizen GC, Anderson GC, Naude TW. A highly fatal tremorgenic mycotoxicosis of cattle caused by Aspergillus clavatus. Onderstepoort J Vet Res 1976; 43:147-54.

74. Sabater-Vilar M, Maas RF, De Bosschere H, Ducatelle R, Fink-Gremmels J. Patulin produced by an Aspergillus clavatus isolated from feed containing malting residues associated with a lethal neurotoxicosis in cattle. Mycopathologia 2004; 158:419-26.

75. Niederberger M, Oevermann A, Kirscher F, Meylan M. Tremorgenic syndrome in a cattle herd after feeding silage contaminated with $A$. clavatus. Schweiz. Arch Tierheilked 2011; 153:105-10.

76. Spencer PS, Schaumburg HH. Chlorinated cyclodienes. In Spencer PS, Schaumburg HH, eds, Experimental and Clinical Neurotoxicology, 2nd ed. Oxford, New York, 2000, pp 364-70.

77. Spencer PS, Daniels JL, Kisby GE. Mustard warfare agents and related substances. In Spencer 
PS, Schaumburg HH, eds, Experimental and Clinical Neurotoxicology, 2nd ed. Oxford, New York, 2000, pp 837-48.

78. Spencer PS, Wilson BW, Albuquerque EX. Sarin, other "nerve agents," and their antidotes. In Spencer PS, Schaumburg HH, eds, Experimental and Clinical Neurotoxicology, $2^{\text {nd }}$ ed. Oxford, New York, 2000, pp 1073-92.

79. Imran M, Mahmood S. An overview of human prion diseases. Virol J 2011; 8:559.

80. Ruiz-Postigo JA, Franco JR, Lado M, Simarro PP. Human African trypanosomiasis in South Sudan: how can we prevent a new epidemic? PLoS Negl Trop Dis 2012; 6(5)e1541.

81. Simarro PP, Cecchi G, Paone M, Franco JR, Diarra A, Ruiz JA, et al. The Atlas of human African trypanosomiasis: a contribution to global mapping of neglected tropical diseases. Int $J$ Health Geogr 2010; 9:57.

82. Brun R, Blum J, Chappuis F, Burri C. Human African trypanosomiasis. Lancet 2010; 375:14859.

83. Noma M, Nwoke BE, Nutall I, Tambala PA, Enyong P, Namsenmo A et al. Rapid epidemiological mapping of onchocerciasis (REMO): its application by the African Programme for Onchocerciasis Control (APOC). Ann Trop Med Parasitol 2002; 96 Suppl 1:S29-39.

84. WHO Expert Committee on Ochocerciasis Control. Onchocerciasis and its control: report of a World Health Organization Expert Committee on Onchocerciasis Control. WHO Geneva, 1995.

85. Boatin B, Molyneux DH, Hougard JM, Christensen OW, Alley ES, Yameogo L et al. Patterns of epidemiology and control of onchocerciasis in west Africa. J Helminthol 1997;71:91-101.

86. Kaiser C, Benninger C, Asaba G, Mugisa C, Kabagambe G, Kipp W, Rating D. Clinical and electro-clinical classification of epileptic seizure in west Uganda. Bull Soc Pathol Exot 2000;93:2559 .

87. Klion AD, Nutman TB. Loiasis and Mansonella infections. In Guerrant RL, Walker DH, Weller PF, eds, Tropical Infectious Diseases. Principles, Pathogens, \& Practice, vol 2, Elsevier, 2006, pp 1163-75.

88. Asio SM, Simonsen PE, Onapa AW. Mansonella perstans filariasis in Uganda: patterns of microfilaraemia and clinical manifestations in two endemic communities. Trans R Soc Trop Med Hyg 2009;103:266-73.
89. Onapa AW, Simonsen PE, Baehr I, Pedersen EM. Rapid assessment of the geographical distribution of Mansonella perstans infections in Uganda, by screening schoolchildren for microfilariae. Ann Trop Med Parasitol 2005;99:38393.

90. Basanez MG, Pion SD, Boakes E, Filipe JA, Churcher TS, Boussinesq M. Effect of singledose ivermectin on Onchocerca volvulus: a systematic review and meta-analysis. Lancet Infect Dis 2008; 8:310-322. S1473-3099(08)70099-9 [pii];10.1016/S1473-3099(08)70099-9 [doi].

91. Duke BO, Zea-Flores G, Castro J, Cupp EW, Munoz B. Effects of multiple monthly doses of ivermectin on adult Onchocerca volvulus. Am J Trop Med Hyg 1990; 43:657-64.

92. Duke BO, Pacque MC, Munoz B, Greene BM, Taylor HR. Viability of adult Onchocerca volvulus after six 2-weekly doses of ivermectin. Bull World Health Orga 1991; 69: 163-8.

93. Duke BO, Zea-Flores G, Castro J, Cupp EW, Munoz B. Comparison of the effects of a single dose and of four six-monthly doses of ivermectin on adult Onchocerca volvulus. Am J Trop Med Hyg 1991; 45: 132-7.

94. Duke BO, Zea-Flores G, Castro J, Cupp EW, Munoz B. Effects of three-month doses of ivermectin on adult Onchocerca volvulus. Am J Trop Med Hyg 1992; 46: 189-94.

95. Awadzi K, Attah SK, Addy ET, Opoku NO, Quartey BT. The effects of high-dose ivermectin regimens on Onchocerca volvulus in onchocerciasis patients. Trans R Soc Trop Med Hyg 1999; 93:18994.

96. Plaisier AP, Alley ES, Boatin BA, van Oortmarssen GJ, Remme H, de Vlas SJ, et al. Irreversible effects of ivermectin on adult parasites in onchocerciasis patients in the Onchocerciasis Control Programme in West Africa. J Infect Dis 1995; 172: 204-10.

97. Plaisier AP, van Oortmarssen GJ, Remme J, Habbema JD. The reproductive lifespan of Onchocerca voluulus in West African savanna. Acta Trop 1991; 48: 271-84.

98. Alley ES, Plaisier AP, Boatin BA, Dadzie KY, Remme J, Zerbo G, Samba EM. The impact of five years of annual ivermectin treatment on skin microfilarial loads in the onchocerciasis focus of Asubende, Ghana. Trans R Soc Trop Med Hyg 1994; 88: 581-4.

99. Boatin BA, Hougard JM, Alley ES, Akpoboua LK, Yameogo L, Dembele N, Seketeli A, Dadzie 
KY. The impact of Mectizan on the transmission of onchocerciasis. Ann Trop Med Parasitol 1998; 92 Suppl 1: S46-S60.

100.Borsboom GJ, Boatin BA, Nagelkerke NJ, Agoua H, Akpoboua KL, Alley EW, et al. Impact of ivermectin on onchocerciasis transmission: assessing the empirical evidence that repeated ivermectin mass treatments may lead to elimination/eradication in West-Africa. Filaria J 2003; 2: 8.

101.Boussinesq M, Prod'hon J, Chippaux JP . Onchocerca volvulus: striking decrease in transmission in the Vina valley (Cameroon) after eight annual large scale ivermectin treatments. Trans R Soc Trop Med Hyg 1997; 91: 82-6.

102.Boussinesq M, Prod'hon J, Chippaux JP, Quillevere D. Long-term effect of a single dose of ivermectin on skin microfilarial density in an endemic onchocerciasis area of North Cameroon. Ann Soc Belg Med Trop 1993; 73: 18996.

103.Cupp EW, Ochoa JO, Collins RC, Cupp MS, Gonzales-Peralta C, Castro J, Zea-Flores G. The effects of repetitive community-wide ivermectin treatment on transmission of Onchocerca volvulus in Guatemala. Am J Trop Med Hyg 1992; 47: 17080.

104. Mectizan Donation Program. Annual Highlights 2011.

105.Awadzi K. Clinical picture and outcome of Serious Adverse Events in the treatment of Onchocerciasis. Filaria J 2003; 2 Suppl 1: S6.

106. Awadzi K, Opoku NO, Addy ET, Quartey BT (1995) The chemotherapy of onchocerciasis. XIX: The clinical and laboratory tolerance of high dose ivermectin. Trop Med Parasitol 1995; 46: 131-7.

107.Awadzi K. The chemotherapy of onchocerciasis II. Quantitation of the clinical reaction to microfilaricides. Ann Trop Med Parasitol 1981; 74: 189-97.

108.Awadzi K, Dadzie KY, De SG, Remme J. Reactions to ivermectin treatment in onchocerciasis patients. Acta Leiden 1990; 59: 1939.

109.De SG, Awadzi K, Remme J, Dadzie KY, Ba O, Giese J, Karam M, et al. A community trial of ivermectin in the onchocerciasis focus of Asubende, Ghana. II. Adverse reactions. Trop Med Parasitol 1989; 40: 375-82.
110.De SG, Remme J, Awadzi K, Accorsi S, Alley $\mathrm{ES}, \mathrm{Ba} \mathrm{O}$, et al. Adverse reactions after largescale treatment of onchocerciasis with ivermectin: combined results from eight community trials. Bull World Health Organ 1989; 67: 707-19.

111.Baraka OZ, Khier MM, Ahmed KM, Ali MM, el Mardi AE, Mahmoud BM, et al. Community based distribution of ivermectin in eastern Sudan: acceptability and early post-treatment reactions. Trans R Soc Trop Med Hygiene 1995; 89:316-8.

112.Baraka OZ, Mahmoud BM, Ali MM, Ali MH, el Sheikh EA, Homeida MM, et al. Ivermectin treatment in severe asymmetric reactive onchodermatitis (sowda) in Sudan. Trans $R$ Soc Trop Med Hygiene 1995; 89:312-5.

113. Boussinesq M, Kamgno J, Pion SD, Gardon J. What are the mechanisms associated with postivermectin serious adverse events? Trends Parasitol 2006; 22: 244-246. S1471-4922(06)00101-2 [pii];10.1016/j.pt.2006.04.006 [doi].

114.Edwards G. Ivermectin: does P-glycoprotein play a role in neurotoxicity? Filaria J 2003; 2 Suppl 1:S8.

115.Lankas GR, Gordon LR. Toxicology. In: Campbell WC, ed, Ivermectin and Abamectin. New York: Springer Verlag, 1989; pp. 89-112.

116.Shoop WL, Soll M. Chemistry, pharmacology and safety of macrocyclic lactones. Ivermectin, abamectin and eprinomectin. In: Vercruysse J, Rew RS, eds, Macrocyclic Lactones in Antiparasitic Therapy. Oxon, New York: CABI Publishing 2002; pp. 1-29.

117.Lankas GR, Cartwright ME, Umbenhauer D. P-glycoprotein deficiency in a subpopulation of CF-1 mice enhances avermectin-induced neurotoxicity. Toxicol Appl Pharmacol 1997; 143:357-65.

118. Mealey KL. Therapeutic implications of the MDR-1 gene. J Vet Pharmacol Ther 2004; 27:25764.

119.Merola VM, Eubig PA. Toxicology of avermectins and milbemycins (macrocylic lactones) and the role of P-glycoprotein in dogs and cats. 2012; Vet Clin North Am Small Anim Pract 42:313-33.

120.Janko C, Geyer J. Moxidectin has a lower neurotoxic potential but comparable brain penetration in P-glycoprotein-deficient CF-1 mice compared to ivermectin. J Vet Pharmacol Ther 2012;10.1111/j.1365-2885.2012.01424.x [doi]. 
121.Edwards G. Ivermectin: does P-glycoprotein play a role in neurotoxicity? Filaria J 2003; 2 Suppl 1: S8.

122.Bourguinat C, Kamgno J, Boussinesq M, Mackenzie CD, Prichard RK, Geary TG. Analysis of the $m d r-1$ gene in patients co-infected with Onchocerca volvulus and Loa loa who experienced a post-ivermectin serious adverse event. Am J Trop Med Hyg 2010; 83:28-32. 83/1/28 [pii];10.4269/ ajtmh.2010.09-0734 [doi].

123.Wise LD, Allen HL, Hoe CM, Verbeke DR, Gerson RJ. Developmental neurotoxicity evaluation of the avermectin pesticide, emamectin benzoate, in Sprague-Dawley rats. Neurotoxicol Teratol 1997; 19:315-26.

124.Lankas GR, Minsker DH, Robertson RT. Effect of ivermectin on reproduction and neonatal toxicity in rats. Food Chem Toxicol 1989; 27:523-9.
125.Spencer PS, Palmer, VS. Interrelationships of undernutrition and neurotoxicity: food for thought and research attention. Neurotoxicology 2012; 33:605-16.

126.Atchinson W, Wolfe C, Hamborsky J., eds. Epidemiology and Prevention of Vaccine- Preventable Diseases. The Pink Book. Course Textbook -12 th ed, 2012.

127. Sawaishi Y, Abe T, Yano T, Ishikawa K, Takada G. SSPE following neonatal measles infection. Pediatr Neurol 1999; 20:63-5.

128.Barrero PR, Grippo J, Viegas M, Mistchenko AC. Wild-type measles virus in brain tissue of children with subacute sclerosing panencephalitis. Emerg Infect Dis 2003; 9:10 